Article

\title{
Short-Term Price Forecasting Models Based on Artificial Neural Networks for Intraday Sessions in the Iberian Electricity Market
}

\author{
Claudio Monteiro ${ }^{1}$, Ignacio J. Ramirez-Rosado ${ }^{2}$, L. Alfredo Fernandez-Jimenez ${ }^{3, *}$ and \\ Pedro Conde ${ }^{1}$ \\ 1 Department of Electrical and Computer Engineering, Faculty of Engineering of the University of \\ Porto (FEUP), Porto 4200-465, Portugal; cdm@fe.up.pt (C.M.); ee10153@fe.up.pt (P.C.) \\ 2 Electrical Engineering Department, University of Zaragoza, Zaragoza 50018, Spain; ijramire@unizar.es \\ 3 Electrical Engineering Department, University of La Rioja, Logroño 26004, Spain \\ * Correspondence: luisalfredo.fernandez@unirioja.es; Tel.: +34-941-299-473
}

Academic Editor: Javier Contreras

Received: 7 June 2016; Accepted: 26 August 2016; Published: 7 September 2016

\begin{abstract}
This paper presents novel intraday session models for price forecasts (ISMPF models) for hourly price forecasting in the six intraday sessions of the Iberian electricity market (MIBEL) and the analysis of mean absolute percentage errors (MAPES) obtained with suitable combinations of their input variables in order to find the best ISMPF models. Comparisons of errors from different ISMPF models identified the most important variables for forecasting purposes. Similar analyses were applied to determine the best daily session models for price forecasts (DSMPF models) for the day-ahead price forecasting in the daily session of the MIBEL, considering as input variables extensive hourly time series records of recent prices, power demands and power generations in the previous day, forecasts of demand, wind power generation and weather for the day-ahead, and chronological variables. ISMPF models include the input variables of DSMPF models as well as the daily session prices and prices of preceding intraday sessions. The best ISMPF models achieved lower MAPEs for most of the intraday sessions compared to the error of the best DSMPF model; furthermore, such DSMPF error was very close to the lowest limit error for the daily session. The best ISMPF models can be useful for MIBEL agents of the electricity intraday market and the electric energy industry.
\end{abstract}

Keywords: short-term forecasting; electricity market prices; Iberian electricity market (MIBEL); daily session prices; intraday session prices

\section{Introduction}

The Iberian electricity market (MIBEL) was created in 2004 as a joint initiative from the governments of Portugal and Spain, involving the integration of their respective electric power systems and their previous electricity markets. The MIBEL allows any consumer in the Iberian region (mainland of Portugal and Spain) to purchase electrical energy under a free competition regime from any producer or retailer acting in that region. It represents a regional electricity market with a remarkable growth of renewable energy production that frequently pushes the most expensive thermal power stations outside the generation scheduling of the wholesale market [1]. The MIBEL consists of the forward markets, managed by the company Iberian Energy Market Operator-Portuguese Division (OMIP) [2], and the daily and intraday markets, both managed by the company Iberian Energy Market Operator-Spanish Division (OMIE) [3]. The daily and intraday markets are organized in a daily session, where next-day sale and electricity purchase transactions are carried out, and in six intraday 
sessions that consider energy offer and demand, which may arise in the hours following the daily viability schedule fixed after the daily session.

Short-term electricity price forecasting (STEPF) has attracted the attention of many researchers in the last years. The previous knowledge on the forecasted hourly prices that will be settled in the pool constitutes very valuable information for any agent involved in the electricity markets. A considerable amount of research has been dedicated to bidding procedures, trading strategies or electricity market offerings-especially for wind farms [4-6], price-makers [7,8], and wind farms enhanced with storage capability [9]—and even for bidding in micro grids with renewable generation [10]. Consequently, accurate price forecasts are of significant interest for electric power plants. Thus, according to pool price forecasts, mainly electric energy producers and also distribution utilities and large customers from the demand-side, can change their bidding policy in order to obtain the maximum profit. However, pool prices are hard to forecast due to some characteristics such as non-stationary mean and variance, multiple seasonality, calendar effect, high volatility and high percentage of outliers [11].

Additionally, the price forecasting can also influence the consumers' demand response [12-14]. On the one hand, effective demand response is related to demand forecasting (as well as renewable power forecasting) and, on the other hand, it is associated with price forecasting for the consumers as well as price forecasting of the pool market. Such demand response has to consider interactions among prices, consumer demands and renewable power generation. Research works are starting to develop advanced STEPF models and several other short-term forecasting models for other technical magnitudes, in diverse spatio-temporal scales, in order to support complex systems for research on demand response [15-17]. In this sense, suitable STEPF models for intraday sessions are expected that also will play a key role in related research developments.

The immediate application of STEPF models in bidding strategies has propelled the development of this kind of forecasting model. Most of the STEPF models reported are focused on the application to the daily market. The techniques used include those of traditional time series such as auto-regressive integrated moving average (ARIMA) [18-21] or other artificial intelligence-based techniques such as artificial neural networks (ANNs) [19,22-25] and fuzzy inference systems (FIS) [26]. Some authors propose hybrid approaches combining two or more techniques in the forecasting model [27-32]. In general, most of the published articles are focused on the description of the forecasting techniques and its application to the daily market. The analysis of the price explanatory variables used to build STEPF models is barely studied [33], although this analysis has been pointed out as the focus on STEPF models for the next years [34].

Only a few published works deal with the development of STEPF models in applications to the intraday prices of an electricity market $[35,36]$, although intraday prices are of prime importance in day-to-day market operations, in particular for applications in trading of power plant productions [37,38], or for applications in implementing effective demand response as mentioned above [12-17,39]. In [35], a strategic energy bidding for a wind power farm is presented including a very brief description of a STEPF model used for intraday session prices forecasting based on classic time series, but their performance in each of the six sessions of the MIBEL is not indicated. Another research work [36] is focused on maximizing the profit of a wind power producer placed in Holland by using day-ahead and cross-border intraday markets; it seems to utilize a classic seasonal autoregressive integrated moving average (SARIMA) modeling, which is not described, for one-month price forecasts in the intraday German market. The hourly prices settled in intraday sessions in the MIBEL have been studied [40,41]. Their correlations [40] or realized volatility [41] have been highlighted, but no STEPF model for intraday session prices in the MIBEL has been presented in scientific literature describing the best selection of input variables among an extensive set of intraday price explanatory variables, by obtaining mean absolute percentage errors (MAPEs) of forecasts for each of the six intraday session prices and also by comparing them with respect to error of the day-ahead price forecast in the MIBEL.

In general, as indicated above, most of the published papers described the forecasting technique: there are advanced versatile techniques with similar accuracy when they are applied to a specific 
STEPF case using the same variables and time period. Sometimes authors compare the results obtained with their models with respect to those reported in other works, using the same data and the same period. This paper is not concentrated on forecasting techniques, but it deals with the "forecasting modelling", that is, on the analysis of extensive sets of explanatory variables and their influence in price forecasts. Furthermore, the forecasting modelling of this paper permits to determine input data and structures of processing appropriate for application to the MIBEL.

This paper presents novel STEPF models developed to be applied to the six intraday sessions of the MIBEL, which are called intraday session models for price forecasts (ISMPF model). The best ISMPF model for each session is described in the paper as well as the selected combination of their input variables. The paper also analyses the forecasting errors achieved using different combinations of input (price explanatory) variables in order to determine the best model which uses the proper combination.

The process for analyzing combinations of explanatory variables is initially used for daily session models for price forecasts (DSMPF models) and for reference models for price estimation (RMPE models) in the daily session of the MIBEL. This process is applied to ISMPF models afterwards in the intraday sessions of the MIBEL. The main characteristics of these models are described in the following paragraphs:

- DSMPF models, developed for the day-ahead hourly price forecasting in the daily session of the MIBEL, consider an extensive set of explanatory variables which include recent prices, regional aggregation of power demands and power generations, hourly time series records of power demand forecasts, wind power generation forecasts and weather forecasts as well as chronological information.

- $\quad$ RMPE models, developed for the estimation of the hourly prices in the daily session, use actual power generations and actual power demands of the day-ahead instead of these variables in the previous day, and the same forecast variables, price variables and chronological information of DSMPF models. They allow the calculation of the lowest limit of error values achievable with the utilized explanatory variables.

- ISMPF models, developed for the hourly price forecasting in the six intraday sessions of the MIBEL, consider the input variables included in DSMPF models as well as the hourly prices of the daily session and hourly prices of previous intraday sessions.

The MIBEL was used to test the models of this paper. On one hand, the best ISMPF models achieved very satisfactory MAPEs for the intraday sessions of the MIBEL, which were lower errors for most of the intraday sessions than the error of the best DSMPF model. On the other hand, the MAPE of the best DSMPF model was very close to the lowest limit error of the best RPME model for the daily session. The best ISMPF model, its performance in the MIBEL and its input variables can constitute valuable information for MIBEL agents of the electricity intraday market and the electric energy industry.

The structure of this paper is the following: Section 2 contains a description of time frameworks for the forecasting models and reference models as well as the characteristics of data corresponding to the MIBEL for hourly price forecast purposes; Section 3 describes RMPE models (reference models) for the hourly prices estimation; Section 4 presents DSMPF models for day-ahead hourly price forecasts; Section 5 describes ISMPF models for hourly price forecasts of the six intraday sessions of the MIBEL; lastly, the conclusions of this paper are presented in Section 6.

\section{Time Frameworks and Data Characteristics for Forecasting Models and Reference Models}

Time frameworks for day-ahead and intraday MIBEL price forecasting models as well as for reference models are described in Section 2.1. Afterwards, Section 2.2 shows data characteristics corresponding to the MIBEL for the hourly price forecasting. 


\subsection{Time Frameworks}

The description of time frameworks corresponding to DSMPF models and reference models is presented in Section 2.1.1; Section 2.1.2 describes a time framework for ISMPF models.

\subsubsection{Time Frameworks for Daily Session Models for Price Forecasts and Reference Models}

Bidding offers to the day-head electricity market and the implementation of other power system operation functions are mainly prepared based on short-term forecasting models that provide forecasted hourly prices of the day-ahead.

DSMPF models use as input variables (price explanatory variables) recorded time series of hourly prices in previous days, regional-aggregated hourly power demands and hourly power generations of most of the types of electricity production in the previous day, forecasts of demand, wind power generation and weather (hourly wind speed, temperature and irradiation) for the day-ahead in the region, and chronological variables.

The time framework of DSMPF models is shown in Figure 1. The price forecast $\hat{p}_{D+1, h \mid D, t}^{d}$ is obtained at hour $t$ of the day $D$ for each hour $h$ of the $24 \mathrm{~h}$ in day $D+1$. The delivery of the price forecast is assumed in hour $t$ of day $D$ which can be any instant prior to the opening of the daily market session and after the moment in which the forecasted variables corresponding to demand and wind power generation for the day $D+1$ are known.

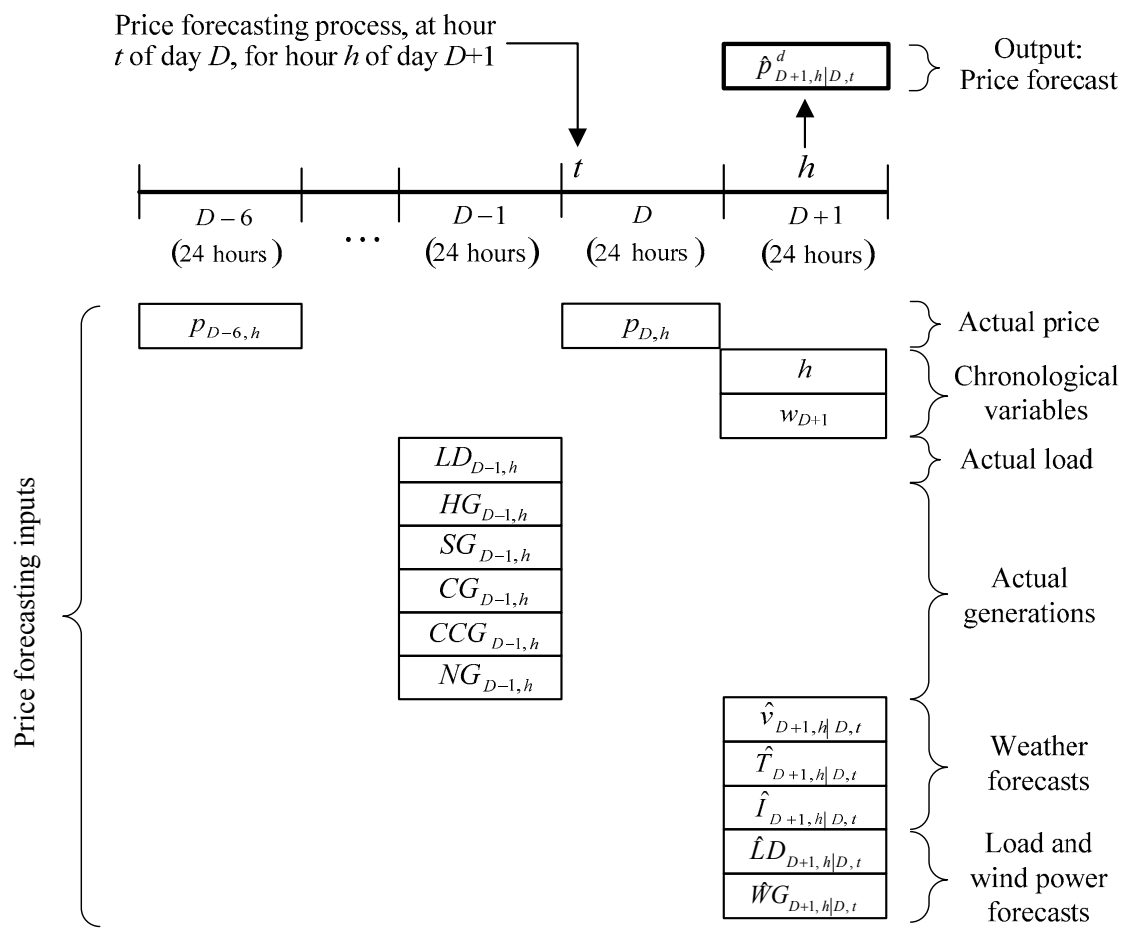

Figure 1. Time framework of daily session models for price forecasts (DSMPF models).

The price for hour $h$ of the day $D, p_{D, h}$, and the price $p_{D-6, h}$ for hour $h$ of day $D-6$, are inputs to forecast the price for the hour $h$ of day $D+1$. Other inputs are the week day $w_{D+1}$ and hour $h$ of day $D+1$, and the weather forecasts obtained at the first hours of day $D$ for the geographical region corresponding to the electricity market and for hour $h$ of day $D+1$, that is, the regional weighted forecasted hourly wind speeds $\hat{v}_{D+1, h \mid D, t}$, regional weighted forecasted hourly temperatures $\hat{T}_{D+1, h \mid D, t}$ and regional weighted forecasted hourly irradiations $\hat{I}_{D+1, h \mid D, t}$. These last inputs are similar to those used by authors in [33].

Diverse input variables were included in Figure 1: power demand $L D_{D-1, h}$, hydropower generation $H G_{D-1, h}$, solar power generation and power cogeneration $S G_{D-1, h}$, coal power generation 
$C G_{D-1, h}$, combined cycle power generation $C C G_{D-1, h}$, and nuclear power generation $N G_{D-1, h}$ at hour $h$ of day $D-1$. Two additional input variables of forecasting available before the opening of the daily session in day $D$ were considered: power demand forecast $\hat{L} D_{D+1, h \mid D, t}$ and wind power generation forecast $\hat{W} G_{D+1, h \mid D, t}$ for hour $h$ of day $D+1$.

Figure 2 illustrates the time framework of the RMPE models. A part of the input variables of the RMPE models, mainly actual power generations and power demands of day $D+1$, as well as the output variable price estimation $\widetilde{p}_{D+1, h}$, are different from the input variables of DSMPF models. Note that DSMPF models mainly use actual power generations and power demands of day $D-1$ as input variables, and the output variable corresponds to the price forecast $\hat{p}_{D+1, h \mid D, t}^{d}$. Thus, RMPE models are not forecasting models, but models for hourly price estimation.

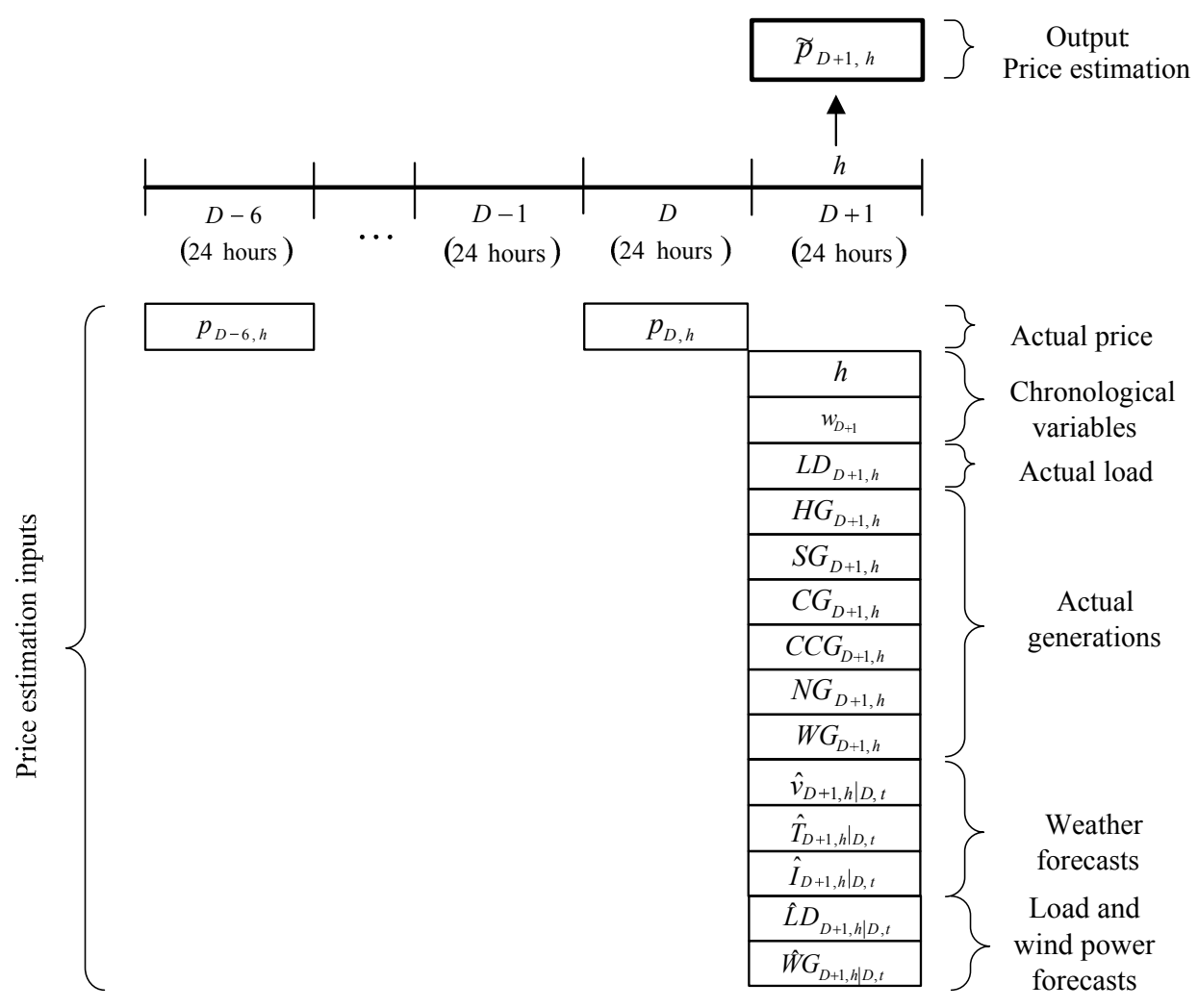

Figure 2. Time framework of reference models for price estimation (RMPE models).

\subsubsection{Time Framework of Intraday Session Models for Price Forecasts}

The MIBEL market is organized in a daily session whose closing time takes place at 12:00 a.m. (Spanish official hour) of day $D$ and six intraday sessions whose structure is given in Table 1. As it is shown, the first intraday session covers the last $3 \mathrm{~h}$ of the current day $(D)$ and the $24 \mathrm{~h}$ of the following day $(D+1)$, that is, a total of $27 \mathrm{~h}$. The other sessions comprise only a shorter time period of day $D+1$. The time period covered by each session is reduced session after session with a minimum of $9 \mathrm{~h}$ in the sixth intraday session.

The time framework for the ISMPF models is illustrated in Figure 3. The input variables of these ISMPF models for a given intraday session can include the hourly prices of previous intraday sessions and the hourly prices of the daily session of the MIBEL, as well as the set of input variables used by DSMPF models. Figure 3 shows in orange the periods in which the forecast can be carried out, from the moment when the prices of the previous session are known (around $45 \mathrm{~min}$ after its closing hour) to the closing hour of the corresponding intraday session. Figure 3 also partially shows in blue the period covered by each market session. 
Table 1. Structure of the Iberian electricity market's (MIBEL's) intraday sessions.

\begin{tabular}{ccccc}
\hline Session Number & $\begin{array}{c}\text { Session Opening } \\
\text { Hour (Spanish Hour) }\end{array}$ & $\begin{array}{c}\text { Session Closing Hour } \\
\text { (Spanish Hour) }\end{array}$ & Time Period & $\begin{array}{c}\text { Hours in } \\
\text { Time Period }\end{array}$ \\
\hline 1 & $17: 00$ & $18: 45$ & $21(D)-23(D+1)$ & 27 \\
2 & $21: 00$ & $21: 45$ & $00(D+1)-23(D+1)$ & 24 \\
3 & $01: 00$ & $01: 45$ & $04(D+1)-23(D+1)$ & 20 \\
4 & $04: 00$ & $04: 45$ & $07(D+1)-23(D+1)$ & 17 \\
5 & $08: 00$ & $08: 45$ & $11(D+1)-23(D+1)$ & 13 \\
6 & $12: 00$ & $12: 45$ & $15(D+1)-23(D+1)$ & 9 \\
\hline
\end{tabular}

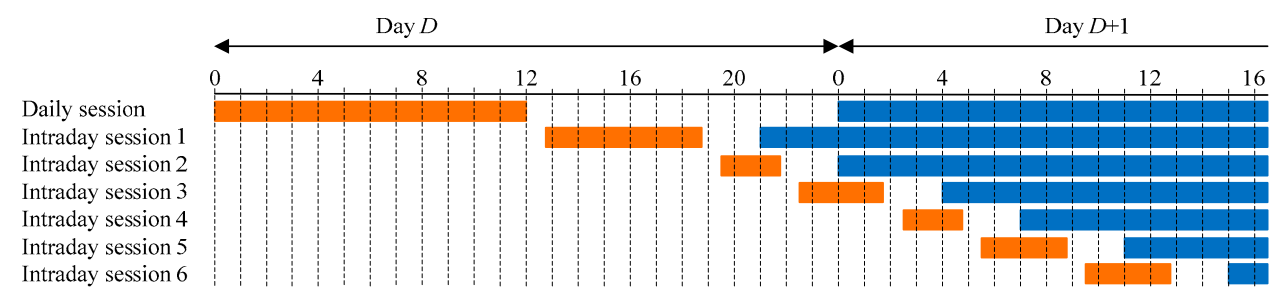

Figure 3. Time framework for outputs of intraday session models for price forecasts (ISMPF models).

\subsection{Data Characteristics}

For the development of the proposed hourly price forecasting models different kinds of variables have been considered, which are the following:

a Actual hourly data prices for the day-ahead and intraday markets available from the market operator OMIE [3].

b Actual hourly data of the power system: load demand, wind power generation, hydropower generation, cogeneration and solar power generation, nuclear power generation, coal power generation, combined cycle power generation and power exchanged with France. These data were obtained by aggregating a very large amount of information from the websites of Redes Energéticas Nacionais (REN), the Portuguese transmission system operator (TSO) [42] and Red Eléctrica de España (REE), the Spanish TSO [43].

c Hourly weather forecasts: weighted average wind speed, solar irradiance and temperature. These forecasted values were obtained with the numerical weather prediction (NWP) mesoscale model WRF NMM [44], initialized with the forecasts provided by the global NWP model GFS [45].

d Hourly variable forecasts of the power system: power demand forecasts and wind power generation forecasts. These forecasts were obtained by aggregating forecast information from the mentioned TSOs.

e Chronological variables (hour, week day).

The data recorded, corresponding to years 2012 and 2013, were divided into an in-sample data set used for training and an out-sample data set used for testing DSMPF, RMPE and ISMPF models. The out-sample data set was composed of complete weeks extracted along the two years of data in order to have a good representation of the different price behaviours along the year. The in-sample and out-sample data sets were defined as follows:

i In-sample data set: all the hours of the days in 2012 and 2013, except those included in the out-sample data set, totalizing 14,184 cases (h).

ii Out-sample data set: all the hours of the weeks with numbers 5, 10, 15, 20, 25, 30, 35, 40, 45, 50 in 2012 , and weeks number 2, 7, 12, 17, 22, 27, 32, 37, 42, 47 in 2013; a total of 3360 cases (h).

The descriptive statistics of the price variable of the data sets used for each forecasting model are shown in Table 2, including their mean value, standard deviation, maximum values (minimum values 
are 0 ), and the total of cases (count of hours). For the total cases of intraday session 1 , we have only considered the $24 \mathrm{~h}$ of the following day instead of the $27 \mathrm{~h}$ covered by this session.

Table 2. Descriptive statistics of price data.

\begin{tabular}{|c|c|c|c|c|c|c|c|c|}
\hline Dataset & Statistic & Daily & Intraday 1 & Intraday 2 & Intraday 3 & Intraday 4 & Intraday 5 & Intraday 6 \\
\hline \multirow{3}{*}{ IN-SAMPLE } & Mean $(€ / M W h)$ & 45.02 & 44.73 & 44.75 & 45.69 & 47.30 & 48.08 & 47.90 \\
\hline & $\begin{array}{c}\text { Standard Deviation } \\
(€ / \mathrm{MWh})\end{array}$ & 16.44 & 16.19 & 16.54 & 16.82 & 16.60 & 17.08 & 18.11 \\
\hline & Count (h) & 14,184 & 14,184 & 14,184 & 11,820 & 10,047 & 7683 & 5319 \\
\hline \multirow{3}{*}{ OUT-SAMPLE } & Mean (€/MWh) & 45.88 & 45.80 & 46.93 & 46.91 & 48.48 & 49.10 & 49.03 \\
\hline & Maximum $(€ / \mathrm{MWh})$ & 86.01 & 129.65 & 180.30 & 119.25 & 129.87 & 137.23 & 148.20 \\
\hline & Count (h) & 3360 & 3360 & 3360 & 2800 & 2380 & 1820 & 1260 \\
\hline
\end{tabular}

Figures 4 and 5, for years 2012 and 2013 respectively, represent the hourly average values of power generation for each power generation type, power demand and price in the MIBEL. The hourly average power demand was quite similar in these years, although there were slight changes in the generation-mix production. In 2013, the renewable power generation (hydro, solar and wind power productions) was higher than in year 2012. For thermal power generation (combined cycles, coal and nuclear power productions), the electricity generation from nuclear power production was almost the same in both years, but there was a reduction in the other two productions, with a more significant reduction in the combined cycles, caused by a difference between coal and natural gas prices favourable to coal prices in 2013. In 2013, mainly due to a higher renewable proportion of power generation, prices decreased an average of around $4.4 € / \mathrm{MWh}$.

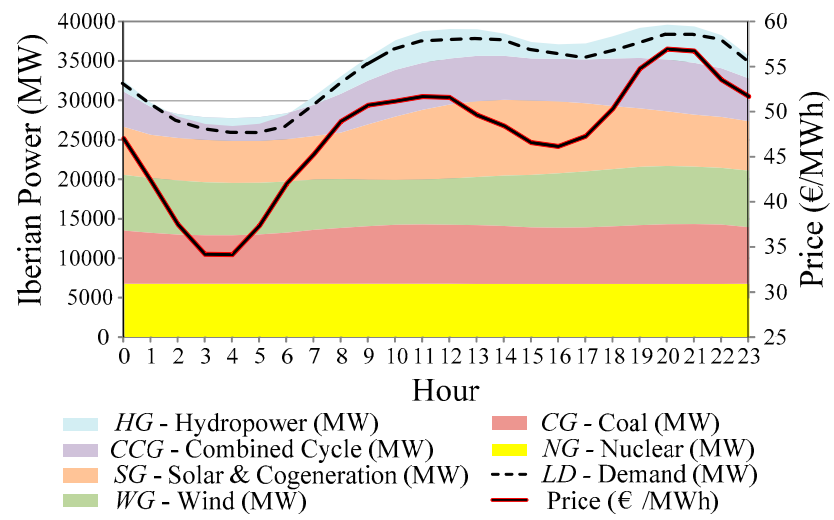

Figure 4. Hourly average power generations, power demand and price in year 2012.

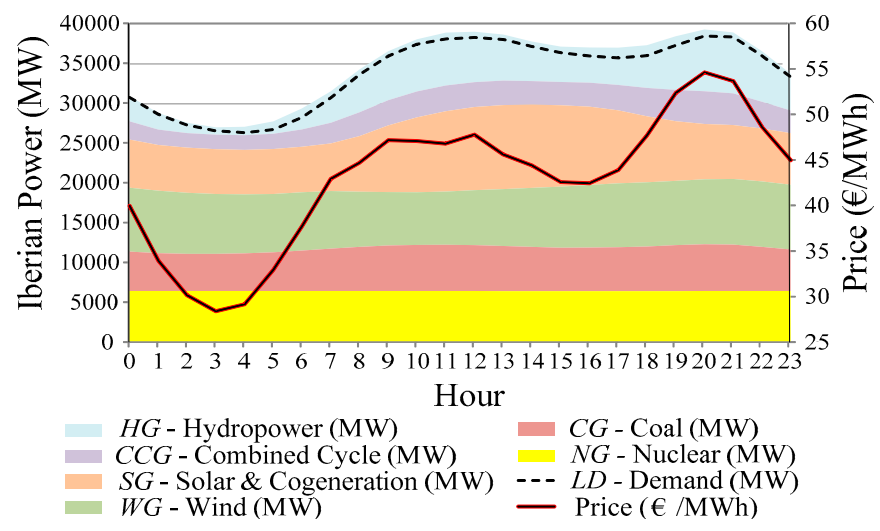

Figure 5. Hourly average power generations, power demand and price in year 2013. 


\section{Reference Models for Price Estimation}

RMPE models are hourly price estimation models that utilize the variables shown in Table 3 as inputs. These input variables include the chronological variables "hour" and "week day" (variables V1 and V2), the prices on previous days at the same hour $h$ (variables V3 and V4), the actual power demand (load) and forecasted power demand variables of the power system for hour $h$ of day $D+1$ (variables V5R and V6R), the actual and forecasted wind power generation variables for hour $h$ of day $D+1$ (variables V7R and V8R), the weather forecasts of wind speed, temperature and irradiance for hour $h$ of day $D+1$ (variables V9R to V11R) and the actual power generations corresponding to hour $h$ of day $D+1$ (variables V12R to V16R).

Table 3. Variables of reference models for price estimation (RMPE models).

\begin{tabular}{ccc}
\hline Variable & Description & Range \\
\hline V1 & Hour & $0-23$ \\
V2 & Week day & Hourly price $D$ \\
V3 & Hourly price $D-6$ & (Monday)-7(special day) \\
V4 & Hourly power demand $D+1$ & $0-110 € / \mathrm{MWh}$ \\
V5R & $0-110 € / \mathrm{MWh}$ \\
V6R & Forecasted hourly power demand $D+1$ & $20,338-52,853 \mathrm{MW}$ \\
V7R & Hourly wind power generation $D+1$ & $18,200-51,839 \mathrm{MW}$ \\
V8R & Forecasted hourly wind power generation $D+1$ & $161-20,198 \mathrm{MW}$ \\
V9R & Forecasted hourly temperature $D+1$ & $427-19,688 \mathrm{MW}$ \\
V10R & Forecasted hourly wind speed $D+1$ & $-0.8-35.8^{\circ} \mathrm{C}$ \\
V11R & Forecasted hourly irradiance $D+1$ & $1.48-11.15 \mathrm{~m} / \mathrm{s}$ \\
V12R & Hourly hydropower generation $D+1$ & $0-1031.8 \mathrm{~W} / \mathrm{m}^{2}$ \\
V13R & Hourly cogeneration and solar power generation $D+1$ & $-3957-15,384 \mathrm{MW}$ \\
V14R & Hourly coal power generation $D+1$ & $3824-13,668 \mathrm{MW}$ \\
V15R & Hourly nuclear power generation $D+1$ & $615-11,604 \mathrm{MW}$ \\
V16R & Hourly combined cycled power generation $D+1$ & $3391-7525 \mathrm{MW}$ \\
\hline
\end{tabular}

We did not explore the relative importance of the different price explanatory variables considered in this paper since it was extensively presented in a previous publication [33]. Instead, in the present article, a set of studies of suitable combinations of input variables for the different type of models (DSMPF, RMPE and ISMPF models) are being described in order to determine the best DSMPF model, the best RMPE model and the best ISMPF model for each intraday session in the MIBEL.

RMPE models contain the variables of the REMPE model introduced by the authors in [33], but now two additional variables are considered: the forecasted hourly power demand for day $D+1$ (variable V6R) and the forecasted hourly wind power generation for day $D+1$ (variable V8R). Then, we formulated the question: "How relevant are these forecasted variables (V6R and V8R) compared to the variables of the actual demand $D+1$ and the actual wind generation $D+1$ (V5R and V7R)?". In order to answer this question, four RMPE models (model REF1 to model REF4) were built, shown in Table 4. In this table, PG means power generation. Please observe that model REF1 is the REMPE model.

RMPE models were implemented with a multilayer perceptron neural network (MLP) [46], using one hidden layer with $2 n+1$ neurons, where $n$ is the number of input variables (explanatory variables). These models were trained and tested with the in-sample and out-sample data sets previously described in Section 2, which were utilized in all computing experiences presented in this paper. Since we used random weight initiation in these neural networks, different training of the same MLP resulted in slightly different computer results (outputs). In order to avoid this inconvenience, we used, as a final forecasting result, the ensemble averaging [47] of the outputs of 20 training processes of the same MLP, thus achieving a more stable response and a lower error. 
Table 4. RMPE models and their mean absolute percentage errors (MAPEs).

\begin{tabular}{|c|c|c|c|c|c|c|}
\hline \multicolumn{2}{|c|}{ Explanatory Variables } & \multirow{3}{*}{$\begin{array}{c}\text { Description } \\
\text { Hour }(0-23 \text { h) } \\
\text { Week day (1-7) }\end{array}$} & \multirow{3}{*}{$\begin{array}{c}\text { REF1 } \\
\bullet \\
\bullet\end{array}$} & \multirow{3}{*}{$\begin{array}{c}\text { REF2 } \\
\bullet \\
\bullet\end{array}$} & \multirow{3}{*}{$\begin{array}{c}\text { REF3 } \\
\bullet \\
\bullet\end{array}$} & \multirow{3}{*}{$\begin{array}{c}\text { REF4 } \\
\bullet \\
\bullet\end{array}$} \\
\hline & V1 & & & & & \\
\hline Chronological & V2 & & & & & \\
\hline \multirow{2}{*}{ Price } & V3 & Hourly price $(D)$ & $\bullet$ & $\bullet$ & $\bullet$ & $\bullet$ \\
\hline & V4 & Hourly price $(D-6)$ & $\bullet$ & $\bullet$ & $\bullet$ & $\bullet$ \\
\hline \multirow{2}{*}{ Demand } & V5R & Hourly power demand $D+1$ & $\bullet$ & - & $\bullet$ & $\bullet$ \\
\hline & V6R & Forecasted hourly power demand $D+1$ & - & $\bullet$ & - & $\bullet$ \\
\hline \multirow{2}{*}{ Wind PG } & V7R & Hourly wind power generation $D+1$ & - & - & - & - \\
\hline & V8R & Forecasted hourly wind power generation $D+1$ & - & - & $\bullet$ & $\bullet$ \\
\hline \multirow{3}{*}{ Weather } & V9R & Forecasted hourly temperature $D+1$ & $\bullet$ & $\bullet$ & $\bullet$ & - \\
\hline & V10R & Forecasted hourly wind speed $D+1$ & - & - & - & - \\
\hline & V11R & Forecasted hourly irradiance $D+1$ & $\bullet$ & $\bullet$ & $\bullet$ & $\bullet$ \\
\hline \multirow{6}{*}{ Other PG } & V12R & Hourly hydropower generation $D+1$ & $\bullet$ & $\bullet$ & $\bullet$ & $\bullet$ \\
\hline & V13R & Hourly cogeneration and solar power generation $D+1$ & - & - & - & - \\
\hline & V14R & Hourly coal power generation $D+1$ & - & - & - & - \\
\hline & V15R & Hourly nuclear power generation $D+1$ & - & - & - & - \\
\hline & V16R & Hourly combined cycled power generation $D+1$ & $\bullet$ & $\bullet$ & $\bullet$ & $\bullet$ \\
\hline & & MAPE (\%) & 10.23 & 9.89 & 10.43 & 9.88 \\
\hline
\end{tabular}

An error analysis for RMPE models using the MAPE was carried out in the price estimations corresponding to the out-sample data set, where the MAPE is defined by Equation (1):

$$
M A P E=\frac{1}{N} \sum_{T=1}^{N} \frac{\left|P_{\text {real_}} T-P_{\text {estimation_T }}\right|}{P_{\text {real__M }}} 100
$$

where $P_{\text {real } \_T}$ is the real hourly price value, $P_{\text {estimation } \_T}$ is the estimation of the hourly price value obtained from each RMPE model, $N$ is the number of elements of the out-sample data set and $P_{\text {real }} M$ is the mean real hourly price value corresponding to that data set.

Variable V6R (forecasted power demand) is used in model REF2 instead of variable V5R (actual power demand) of model REF1. Thus, the MAPEs of Table 4 indicate that the forecasted power demand (for day $D+1$ ) explains electricity prices better than the actual power demand (of day $D+1$ ).

We repeated the experience using variable V8R (forecasted wind power generation) in model REF3 instead of variable V7R (actual wind power generation) in model REF1. Then, the MAPEs of Table 4 indicate that the actual wind power generation (of day $D+1$ ) explains electricity prices better than the forecasted wind power generation (of day $D+1$ ). Furthermore, model REF4 including all variables leads to a MAPE value almost equal to that of model REF2.

Therefore, RMPE models can achieve the best MAPE value of approximately $9.9 \%$. It represents the lowest error ("minimum error") using the considered explanatory variables, that is, the lowest limit of the possible performance of any model for price estimation or for price forecast belonging to the same class of models with a similar kind of variables to those used in RMPE models.

\section{Daily Session Models for Price Forecasts}

The inputs of DSMPF models are:

a Chronological variables ("hour" and "week day");

b Hourly prices of days $D$ and $D-6$;

c Recorded hourly power demand and hourly power generations of days $D-1$;

d Hourly power demand forecasts and hourly wind power generation forecast for day $D+1$; and

e Hourly weather forecasts of wind speed, temperature and irradiance for day $D+1$.

Then, DSMPF models take into consideration the sets of input variables shown in Table 5. Obviously, variables of DSMPF models V6, V7, V8, V9 and V10 correspond to variables V6R, V9R, V10R, V11R and V8R used in RMPE models (Table 3). 
Table 5. Variables of daily session models for price forecasts (DSMPF models).

\begin{tabular}{ccc}
\hline Variable & Description & Range \\
\hline V1 & Hour & $0-23$ \\
V2 & Week day & Hourly price $D$ \\
V3 & Hourly price $D-6$ & (Monday)-7 (special day) \\
V4 & Hourly power demand $D-1$ & $0-110 € / \mathrm{MWh}$ \\
V5 & Forecasted hourly power demand $D+1$ & $0-110 € / \mathrm{MWh}$ \\
V6 & Forecasted hourly temperature $D+1$ & $20,338-52,853 \mathrm{MW}$ \\
V7 & Forecasted hourly wind speed $D+1$ & $18,200-51,839 \mathrm{MW}$ \\
V8 & Forecasted hourly irradiance $D+1$ & $-0.8-35.8{ }^{\circ} \mathrm{C}$ \\
V9 & Forecasted hourly wind power generation $D+1$ & $1.48-11.15 \mathrm{~m} / \mathrm{s}$ \\
V10 & Hourly hydropower generation $D-1$ & $0-1031.8 \mathrm{~W} / \mathrm{m}{ }^{2}$ \\
V11 & Hourly cogeneration and solar power generation $D-1$ & $427-19,688 \mathrm{MW}$ \\
V12 & Hourly coal power generation $D-1$ & $3857-15,384 \mathrm{MW}$ \\
V13 & Hourly nuclear power generation $D-1$ & $615-11,604 \mathrm{MW}$ \\
V14 & Hourly combined cycled power generation $D-1$ & $3391-7525 \mathrm{MW}$ \\
V15 & & $336-15,172 \mathrm{MW}$ \\
\hline
\end{tabular}

DSMPF models were implemented with MLPs with the same structure used for the RMPE models, that is, one hidden layer with $2 n+1$ neurons, where $n$ is the number of input explanatory variables. For the training and testing of the MLP, in-sample and out-sample data sets previously described in Section 2 were used again, as well as the abovementioned ensemble technique for the corresponding computer results.

In a similar way than that followed for RMPE models, the MAPE was calculated for the price forecasts corresponding to the out-sample data set for DSMPF models. In this case, the MAPE is defined by Equation (2):

$$
M A P E=\frac{1}{N} \sum_{T=1}^{N} \frac{\left|P_{\text {real_} \_T}-P_{\text {forecast_T }}\right|}{P_{\text {real_M }}} 100
$$

where $P_{\text {real_t }}$ is the real hourly price value, $P_{\text {forecast_}} T$ is the forecasted hourly price value of the forecasting model, $N$ is the number of elements in the out-sample data set, and $P_{\text {real_}} M$ is the mean real hourly price value corresponding to that data set.

In the following paragraphs, a summary of variable selection studies for DSMPF models is shown corresponding to reasonable combinations of variables (grouped by their common characteristics) in order to look for the best MAPE, that is, the best DSMPF model.

The MAPEs for DSMPF models (M1 to M18), with different input variables, are presented in Table 6. The selection of variables follows an ordered analysis, such that only some DSMPF models are presented in the table for conclusive purposes. The construction of Table 6 corresponds to a selection process with the following sequence:

i Models M1 to M3 for price variables selection;

ii Models M4 and M5 for selection of power demand and forecasted power demand variables;

iii Models M6 to M11 for selection of forecasted weather and wind generation variables; and

iv Models M12 to M18 for power generation variables selection.

Model M1 is a simple baseline model with a MAPE value of $20.83 \%$, slightly higher than the double of $9.9 \%$ achieved by the best RMPE model. As mentioned in the previous section, $9.9 \%$ is the lowest limit error value that RMPE models or DSMPF models could obtain. 
Table 6. DSMPF models and their MAPEs.

\begin{tabular}{|c|c|c|c|c|c|c|c|c|c|c|c|c|c|c|c|c|c|c|c|}
\hline \multicolumn{2}{|c|}{ Explanatory Variables } & \multirow{2}{*}{$\begin{array}{c}\text { M1 } \\
\bullet \\
\bullet\end{array}$} & \multirow{2}{*}{$\begin{array}{c}\text { M2 } \\
\bullet \\
\bullet\end{array}$} & \multirow{2}{*}{$\begin{array}{c}\text { M3 } \\
\bullet \\
\bullet\end{array}$} & \multirow{2}{*}{$\begin{array}{c}\text { M4 } \\
\bullet \\
\bullet\end{array}$} & \multirow{2}{*}{$\begin{array}{c}\text { M5 } \\
\bullet \\
\bullet\end{array}$} & \multirow{2}{*}{$\begin{array}{c}\text { M6 } \\
\bullet \bullet\end{array}$} & \multirow{2}{*}{$\begin{array}{c}\text { M7 } \\
\bullet \\
\bullet\end{array}$} & \multirow{2}{*}{$\begin{array}{c}\text { M8 } \\
\bullet \bullet \\
\bullet\end{array}$} & \multirow{2}{*}{$\begin{array}{c}\text { M9 } \\
\bullet \\
\bullet\end{array}$} & \multirow{2}{*}{$\begin{array}{c}\text { M10 } \\
\bullet\end{array}$} & \multirow{2}{*}{\begin{tabular}{c} 
M11 \\
\hdashline$\bullet$
\end{tabular}} & \multirow{2}{*}{$\begin{array}{c}\text { M12 } \\
\bullet\end{array}$} & \multirow{2}{*}{\begin{tabular}{c} 
M13 \\
\hdashline$\bullet$
\end{tabular}} & \multirow{2}{*}{$\begin{array}{c}\text { M14 } \\
\bullet\end{array}$} & \multirow{2}{*}{$\begin{array}{c}\text { M15 } \\
\bullet \bullet\end{array}$} & \multirow{2}{*}{$\begin{array}{c}\text { M16 } \\
\bullet \\
\bullet\end{array}$} & \multirow{2}{*}{\begin{tabular}{c} 
M17 \\
\hdashline$\bullet$
\end{tabular}} & \multirow{2}{*}{$\begin{array}{c}\text { M18 } \\
\bullet \bullet \\
\bullet\end{array}$} \\
\hline Chronological & $\begin{array}{l}\text { V1 } \\
\text { V2 }\end{array}$ & & & & & & & & & & & & & & & & & & \\
\hline Price & $\begin{array}{l}\text { V3 } \\
\text { V4 }\end{array}$ & $\begin{array}{l}- \\
-\end{array}$ & $\begin{array}{l}\bullet \\
-\end{array}$ & $\bullet$ & $\bullet$ & $\bullet$ & $\bullet$ & $\bullet$ & $\bullet$ & $\bullet$ & $\bullet$ & $\bullet$ & $\bullet$ & $\bullet$ & $\bullet$ & $\bullet$ & $\bullet$ & $\bullet$ & $\bullet$ \\
\hline Demand & $\begin{array}{l}\text { V5 } \\
\text { V6 }\end{array}$ & - & - & - & $\begin{array}{l}\bullet \\
-\end{array}$ & $\bullet$ & $\bullet$ & $\bullet$ & $\bullet$ & $\bullet$ & $\bullet$ & $\bullet$ & $\bullet$ & $\bullet$ & $\bullet$ & $\bullet$ & $\bullet$ & $\bullet$ & $\bullet$ \\
\hline & $\begin{array}{l}\text { V7 } \\
\text { V8 } \\
\text { V9 }\end{array}$ & $\begin{array}{l}- \\
- \\
-\end{array}$ & - & - & - & $\begin{array}{l}- \\
-\end{array}$ & $\bullet$ & - & $\begin{array}{l}\text { - } \\
- \\
\bullet\end{array}$ & $\begin{array}{l}- \\
- \\
-\end{array}$ & - & $\begin{array}{l}\bullet \\
- \\
-\end{array}$ & $\begin{array}{l}\bullet \\
- \\
-\end{array}$ & $\begin{array}{l}\bullet \\
- \\
-\end{array}$ & $\begin{array}{l}\bullet \\
- \\
-\end{array}$ & $\begin{array}{l}\bullet \\
- \\
-\end{array}$ & $\begin{array}{l}\bullet \\
- \\
-\end{array}$ & $\begin{array}{l}\bullet \\
- \\
-\end{array}$ & $\begin{array}{l}\bullet \\
- \\
-\end{array}$ \\
\hline Power generation & $\begin{array}{l}\text { V10 } \\
\text { V11 } \\
\text { V12 } \\
\text { V13 } \\
\text { V14 } \\
\text { V15 } \\
\end{array}$ & $\begin{array}{l}- \\
- \\
- \\
- \\
- \\
-\end{array}$ & $\begin{array}{l}- \\
- \\
- \\
- \\
- \\
-\end{array}$ & $\begin{array}{l}- \\
- \\
- \\
- \\
- \\
-\end{array}$ & $\begin{array}{l}- \\
- \\
- \\
- \\
- \\
-\end{array}$ & $\begin{array}{l}- \\
- \\
- \\
- \\
- \\
-\end{array}$ & $\begin{array}{l}- \\
- \\
- \\
- \\
- \\
-\end{array}$ & $\begin{array}{l}- \\
- \\
- \\
- \\
- \\
-\end{array}$ & $\begin{array}{l}- \\
- \\
- \\
-\end{array}$ & $\begin{array}{l}\bullet \\
- \\
- \\
- \\
- \\
-\end{array}$ & $\begin{array}{l}\bullet \\
- \\
- \\
- \\
- \\
-\end{array}$ & $\begin{array}{l}\bullet \\
- \\
- \\
- \\
- \\
-\end{array}$ & $\begin{array}{l}\bullet \\
\bullet \\
- \\
- \\
- \\
-\end{array}$ & $\begin{array}{l}\bullet \\
- \\
- \\
-\end{array}$ & $\begin{array}{l}\bullet \\
- \\
- \\
\bullet \\
- \\
-\end{array}$ & $\begin{array}{l}\bullet \\
- \\
- \\
- \\
\bullet \\
-\end{array}$ & $\begin{array}{l}\bullet \\
- \\
- \\
- \\
- \\
\bullet\end{array}$ & $\begin{array}{l}\bullet \\
\bullet \\
\bullet \\
- \\
- \\
-\end{array}$ & $\begin{array}{l}\bullet \\
\bullet \\
- \\
\bullet \\
\bullet \\
\bullet\end{array}$ \\
\hline MAPE (\%) & & 20.83 & 17.00 & 16.81 & 16.70 & 16.33 & 16.37 & 12.85 & 16.40 & 11.64 & 11.86 & 11.58 & 10.86 & 11.41 & 11.54 & 11.43 & 11.54 & 11.00 & 10.69 \\
\hline
\end{tabular}

If variable V3 (hourly price $D$ ) is added to those used by model M1 leading to model M2, then the MAPE decreases to $17 \%$. The inclusion of variable V5 (hourly power demand $D-1$ ) in model M4 slightly reduces the MAPE to $16.70 \%$. Additionally, if variable V6 (hourly forecasted power demand $D+1$ ) is included (model M5), the MAPE is reduced to $16.33 \%$.

Models M6-M9, compared to model M5, show an added price explicability by including variables V7-V10 (forecasted weather variables and forecasted wind power generation variable). The forecasted wind power generation variable (V10) in model M9 provides a better performance (MAPE of $11.64 \%$ ). Alternatively, the forecasted wind speed variable (V8) in model M7 obtains a MAPE of $12.85 \%$.

The two variables V8 and V10 have collinear information, leading to an error of $11.86 \%$ (in model M11), which is worse than error $11.64 \%$ considering only variable V10 in model M9. However, the use of variable V10 together with variable V7 (forecasted temperature $D+1$ ) improves the performance to a better MAPE value (11.58\%) in model M11.

Models M12 to M16 allow the evaluation of the improvement in the MAPE by adding variables V11 to V15 (power generation variables $D-1$ ). Variable V11 (hydropower generation $D-1$ ) is the one that achieves a lower error, $10.86 \%$ in model M12. The inclusion of variables V13 to V15 (thermal power generation $D-1$ ) to the previous model M12 results in the best performance of DSMPF models (model M18), reaching a MAPE value of $10.69 \%$, which is very satisfactory in comparison to the aforementioned lowest limit error value of $9.9 \%$ of RMPE models.

Figure 6 shows an example of the hourly evolution of actual price values and forecasts of model M18 for week 7 of year 2013.

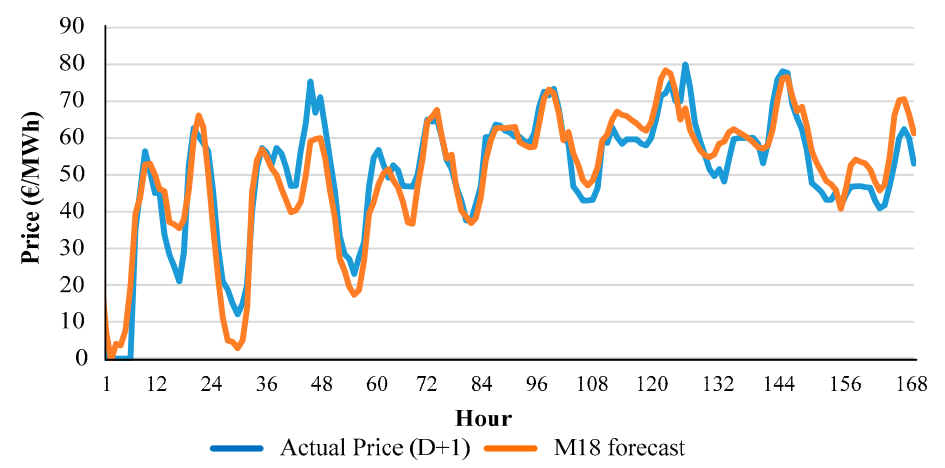

Figure 6. Actual price values and forecast values of model M18 for week 7 of year 2013.

\section{Intraday Session Models for Price Forecasts}

As indicated in the "Introduction" section, this paper is focused on the ISMPF models corresponding to the six intraday sessions of the MIBEL. 
ISMPF models of each intraday session are short-term hourly price forecasting models that can utilize hourly prices on previous days $D$ and $D-6$, price values of the daily session and price values of previous intraday sessions of the MIBEL. They also include recorded explanatory variables mainly corresponding to days $D-1$ and weather forecasts of day $D+1$, as well as power demand forecasts and wind power generation forecasts for day $D+1$ in order to forecast the electricity price values of the intraday sessions of the MIBEL.

Thus, six types of explanatory variables were considered in ISMPF models for a given intraday session:

- Chronological variables ("hour" and "week day");

- Hourly prices of days $D$ and $D-6$;

- Hourly prices of the daily session $D+1$ and hourly prices of previous intraday sessions of the MIBEL;

- Hourly power demand and hourly power generations of days $D-1$;

- Hourly power demand forecasts and hourly wind power generation forecasts for day $D+1$;

- Hourly weather forecasts of wind speed, temperature and irradiance for day $D+1$.

Then, ISMPF models consider the sets of input variables shown in Table 7. Obviously, variables V6I to V16I of ISMPF models correspond to variables V5 to V15 used in DSMPF models (Table 5).

ISMPF models were implemented with MLPs with the same structure used for DSMPF models, that is, one hidden layer with $2 n+1$ neurons, where $n$ is the number of input explanatory variables. For the training and testing of the MLP, in-sample and out-sample data sets previously described in Section 2 were used again as well as the ensemble technique for the corresponding computer results.

In a similar way to that used for DSMPF models, the MAPE was calculated for the price forecasts corresponding to the out-sample data set for DSMPF models. In this case, the MAPE for intraday session $k$ is defined by Equation (3):

$$
M A P E_{k}=\frac{1}{N_{k}} \sum_{T=1}^{N_{k}} \frac{\left|P_{k \text { real_T }}-P_{k \text { forecast_T } T}\right|}{P_{\text {real_MNk }}} 100
$$

where $P_{k \text { real } \_T}$ is the real hourly price value, $P_{k \text { forecast_ } T}$ is the forecasted hourly price value of the forecasting model of intraday session $k, N_{k}$ is the number of elements (h) in the out-sample data set and $P_{\text {real_MNk }}$ is the mean real hourly price value corresponding to that data set. The values for $N_{k}$ were $3360 \mathrm{~h}$ for intraday sessions 1 and 2, $2800 \mathrm{~h}$ for intraday session 3, $2380 \mathrm{~h}$ for intraday session 4 , $1820 \mathrm{~h}$ for intraday session 5 , and $1260 \mathrm{~h}$ for intraday session 6.

Table 7. Variables of ISMPF models.

\begin{tabular}{ccc}
\hline Variable & Description & Range \\
\hline V1 & Hour & $0-23$ \\
V2 & Week day & Hourly price $D$ \\
V3 & Hourly price $D-6$ & (Monday)-7 (special day) \\
V4 & Hourly price $D+1$ of daily session & $0-110 € / \mathrm{MWh}$ \\
V5I & Hourly power demand $D-1$ & $0-110 € / \mathrm{MWh}$ \\
V6I & Forecasted hourly power demand $D+1$ & $0-110 € / \mathrm{MWh}$ \\
V7I & Forecasted hourly temperature $D+1$ & $20,338-52,853 \mathrm{MW}$ \\
V8I & Forecasted hourly wind speed $D+1$ & $18,200-51,839 \mathrm{MW}$ \\
V9I & Forecasted hourly irradiance $D+1$ & $-0.8-35.8{ }^{\circ} \mathrm{C}$ \\
V10I & Forecasted hourly wind power generation $D+1$ & $1.48-11.15 \mathrm{~m} / \mathrm{s}$ \\
V11I & Hourly hydropower generation $D-1$ & $0-1031.8 \mathrm{~W} / \mathrm{m}{ }^{2}$ \\
V12I & Hourly coal power generation $D-1$ & $427-19,688 \mathrm{MW}$ \\
V13I & Hourly cogeneration and solar power generation $D-1$ & $-3957-15,384 \mathrm{MW}$ \\
V14I & Hourly nuclear power generation $D-1$ & $3824-13,668 \mathrm{MW}$ \\
V15I & Hourly combined cycled power generation $D-1$ & $615-11,604 \mathrm{MW}$ \\
V16I & Hourly price $D+1$ from intraday session 1 & $3391-7525 \mathrm{MW}$ \\
V17I & Hourly price $D+1$ from intraday session 2 & $336-15,172 \mathrm{MW}$ \\
V18I & Hourly price $D+1$ from intraday session 3 & $0-132.22 € / \mathrm{MWh}$ \\
V19I & Hourly price $D+1$ from intraday session 4 & $0-80.30 € / \mathrm{MWh}$ \\
V20I & Hourly price $D+1$ from intraday session 5 & $0-180.30 € / \mathrm{MWh}$ \\
V21I & & $0-131.57 € / \mathrm{MWh}$ \\
\hline
\end{tabular}


A summary of variable selection studies of ISMPF models for each intraday session will be presented in Sections 5.1-5.6, corresponding to reasonable combinations of explanatory variables (grouped by their common characteristics) that allow to achieve the best ISMPF model of such intraday session.

Following a similar process to that used to select suitable variables for DSMPF models (in previous Section 4), a significant number of combinations of variables were analysed for the six intraday sessions, but only ISMPF models that led to relevant conclusions are going to be presented.

The procedure of analysis was based on a sequential integration of a different kind of variables by the following order of importance:

i Chronological variables V1 and V2 (hour and week day);

ii Price variables, including price $D-1$, price $D-6$, price $D+1$ of daily session, and price $D+1$ of previous intraday sessions;

iii Power demand $D-1$ and forecasted power demand $D+1$;

iv Forecasted weather $D+1$ and forecasted wind power generation $D+1$;

v Power generations $D-1$.

An ISMPF model that includes the price $D+1$ of the daily session (clearing hourly price for the day ahead $D+1$ ) and the price $D+1$ of previous intraday sessions (clearing hourly price $D+1$ from previous intraday sessions) can be used immediately after the clearing market for the sessions whose prices are included as inputs in the ISMPF model. Simpler ISMPF models that do not include these variables can be utilized at the first hours of day $D$ in a similar way to DSMPF models presented in Section 4.

Descriptions of ISMPF models for each intraday session are presented in the next paragraphs.

\subsection{Intraday Market Session 1}

The baseline model S1M1 in Table 8 that uses only chronological information (variables V1 and V2) has a MAPE close to $20 \%$. This order of magnitude of the error was similar for most of the intraday sessions (models S1M1, S2M1, S3M1, S4M1 and S5M1) and it was slightly lower than the error of model M1 (Table 6) for the daily session. Notice that Tables 9-13 give the MAPEs of baseline models S2M1, S3M1, S4M1, S5M1 and S6M1 for intraday sessions 2-6.

Table 8. ISMPF models for intraday session 1 and their MAPEs.

\begin{tabular}{|c|c|c|c|c|c|c|c|c|c|c|c|}
\hline \multicolumn{2}{|c|}{ Explanatory Variables } & \multirow{3}{*}{$\begin{array}{c}\text { Description } \\
\text { Hour }(0-23 \text { h) } \\
\text { Week day }(1-7)\end{array}$} & \multirow{3}{*}{$\begin{array}{c}\text { S1M1 } \\
\bullet \\
\bullet\end{array}$} & \multirow{3}{*}{$\begin{array}{c}\text { S1M2 } \\
\bullet \\
\bullet\end{array}$} & \multirow{3}{*}{$\begin{array}{c}\text { S1M3 } \\
\bullet \\
\bullet\end{array}$} & \multirow{3}{*}{$\begin{array}{c}\text { S1M4 } \\
\bullet \\
\bullet\end{array}$} & \multirow{3}{*}{$\begin{array}{c}\text { S1M5 } \\
\bullet\end{array}$} & \multirow{3}{*}{$\begin{array}{c}\text { S1M6 } \\
\bullet \\
\bullet\end{array}$} & \multirow{3}{*}{$\begin{array}{c}\text { S1M7 } \\
\bullet \\
\bullet\end{array}$} & \multirow{3}{*}{$\begin{array}{c}\text { S1M8 } \\
\bullet \\
\bullet\end{array}$} & \multirow{3}{*}{$\begin{array}{c}\text { S1M9 } \\
\bullet \\
\bullet\end{array}$} \\
\hline Chronological & $\mathrm{V} 1$ & & & & & & & & & & \\
\hline Chronological & $\mathrm{V} 2$ & & & & & & & & & & \\
\hline \multirow{3}{*}{ Price } & V3 & Hourly price $(D)$ & - & $\bullet$ & - & - & $\bullet$ & $\bullet$ & - & - & - \\
\hline & V4 & Hourly price $(D-6)$ & - & - & - & - & - & $\bullet$ & - & - & - \\
\hline & V5I & Hourly price $(D+1)$ from daily session & - & - & - & $\bullet$ & $\bullet$ & $\bullet$ & $\bullet$ & $\bullet$ & $\bullet$ \\
\hline \multirow{2}{*}{ Demand } & V6I & Hourly power demand $(D-1)$ & - & - & - & - & - & - & $\bullet$ & - & - \\
\hline & V7I & Forecasted hourly power demand $(D+1)$ & - & - & - & - & - & - & $\bullet$ & - & - \\
\hline \multirow{3}{*}{ Weather } & V8I & Forecasted hourly temperature $(D+1)$ & - & - & - & - & - & - & - & $\bullet$ & - \\
\hline & V9I & Forecasted hourly wind speed $(D+1)$ & - & - & - & - & - & - & - & $\bullet$ & - \\
\hline & V10I & Forecasted hourly irradiance $(D+1)$ & - & - & - & - & - & - & - & $\bullet$ & - \\
\hline \multirow{6}{*}{$\begin{array}{l}\text { Power } \\
\text { generation }\end{array}$} & V11I & $\begin{array}{l}\text { Forecasted hourly wind power } \\
\text { generation }(D+1)\end{array}$ & - & - & - & - & - & - & - & $\bullet$ & - \\
\hline & V12I & Hourly hydropower generation $(D-1)$ & - & - & - & - & - & - & - & - & $\bullet$ \\
\hline & V13I & $\begin{array}{c}\text { Hourly cogeneration and solar power } \\
\text { generation }(D-1)\end{array}$ & - & - & - & - & - & - & - & - & $\bullet$ \\
\hline & V14I & Hourly coal power generation $(D-1)$ & - & - & - & - & - & - & - & - & $\bullet$ \\
\hline & V15I & \multirow{2}{*}{$\begin{array}{c}\text { Hourly nuclear power generation }(D-1) \\
\text { Hourly combined cycled power } \\
\text { generation }(D-1)\end{array}$} & - & - & - & - & - & - & - & - & $\bullet$ \\
\hline & V16I & & - & - & - & - & - & - & - & - & $\bullet$ \\
\hline \multicolumn{3}{|r|}{ MAPE (\%) } & 19.95 & 16.56 & 19.64 & 7.49 & 7.84 & 7.51 & 7.59 & 7.49 & 7.48 \\
\hline
\end{tabular}

In order to consider the price variables (variables V3, V4 and V5I), the performances of models S1M2, S1M3 and S1M4 of Table 8 were evaluated. Comparing model S1M3 (error of 19.64\%) and model 
S1M1 (error of $19.95 \%$ ), we can observe that variable V4, price $D-6$, led to a small improvement. The integration of variable V3, price $D$, in model S1M2 has a more significant improvement (error of $16.56 \%$ ). If prices $D+1$ of the daily session are available, then this variable V5I can be used in ISMPF models. By including this variable V5I, model S1M4 achieved a MAPE of 7.49\%. Therefore, with a relatively simple model (with only three variables V1, V2 and V5I), it is possible to obtain price forecasts of the intraday session 1 with a relatively low error value. The error for the intraday session $1(7.49 \%)$ was clearly lower than the error for the daily session $(10.69 \%)$, obtained with the best DSMPF model (model M18) of Table 6. Models S1M5 and S1M6 allowed to test combinations of price explanatory variables; in both models, the performances were worse than that of model S1M4, since model S1M5 obtained an error of 7.84\% and model S1M6 an error of 7.51\%, whereas model S1M4 achieved an error of $7.49 \%$ (using only variable V5I).

The integration of power demand variables was tested for different combinations of variables V6I and V7I, with no improvement in performances with respect to model S1M4. Model S1M7 is one of these tested models; it uses these variables V6I and V7I combined with the variables used in model S1M4; and model S1M7 reached a worse result (error of 7.59\%) than that of model S1M4 (error of 7.49\%).

The consideration of forecasted weather variables (variables V8I, V9I and V10I) and also the forecasted hourly wind power generation (variable V11I), all for day $D+1$, were also studied (in model S1M8) with no improvement of the error with respect to model S1M4. Finally, using the variables of model S1M4, the integration of variables V12I to V16I (power generations $D-1$ ) was carried out in model S1M9, which obtained a satisfactory performance with an error of $7.48 \%$, almost equal to that of the simpler model S1M4. Thus, this simpler model S1M4 was preferred.

Figure 7 shows an example of the hourly evolution of actual price values and forecast values of model S1M4 for week 7 of year 2013.

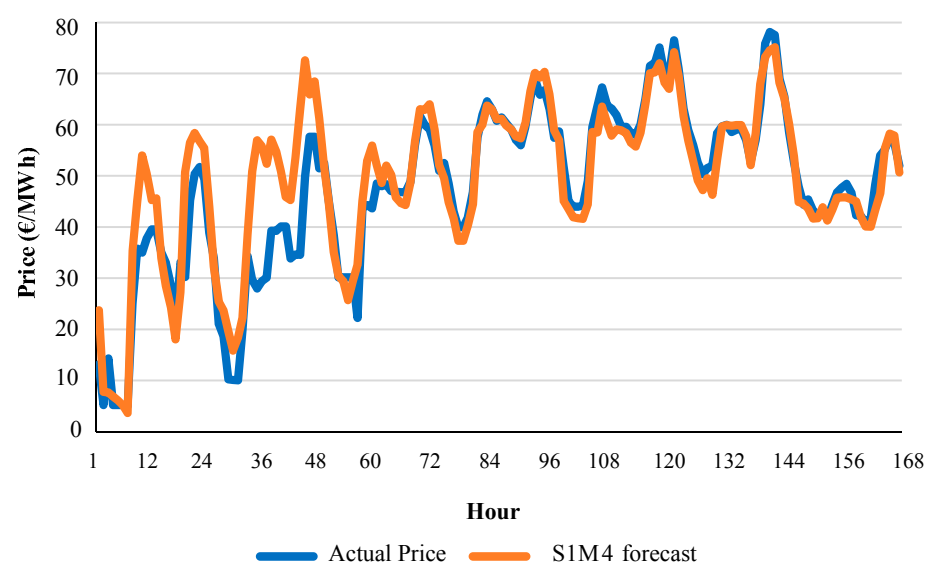

Figure 7. Actual price values and forecast values of model S1M4 of intraday session 1 for week 7 of year 2013.

\subsection{Intraday Market Session 2}

Let consider the possibility that variable V17I (the price $D+1$ of intraday session 1 of the MIBEL) is available for ISMPF models for intraday market session 2. Models S2M2 to S2M5 of Table 9 tested the integration of each individual price variable (variables V3, V4, V5I and V17I) within baseline model S2M1. Thus, variable V3 (hourly price $D$ ) in model S2M2 (error of $16.71 \%$ ) is clearly preferred with respect to variable V4 (hourly price $D-6$ ) in model S2M3 (error of $19.61 \%$ ). By integrating variables V5I (hourly price $D+1$ of daily session) or V17I (hourly price $D+1$ of intraday session 1 ) in model S2M1, model S2M4 led to an error of $9.84 \%$ and model S2M5 to $9.95 \%$. Combining the two variables V5I and V17I with the variables of model S2M1, model S2M6 achieved the best MAPE of $8.85 \%$ among ISMPF models of intraday session 2. Please note that the performance of this model S2M6 (error of $8.85 \%$ ) was higher than the best model S1M4 of intraday market session 1 (error of $7.49 \%$ ). 
Table 9. ISMPF models for intraday session 2 and their MAPEs.

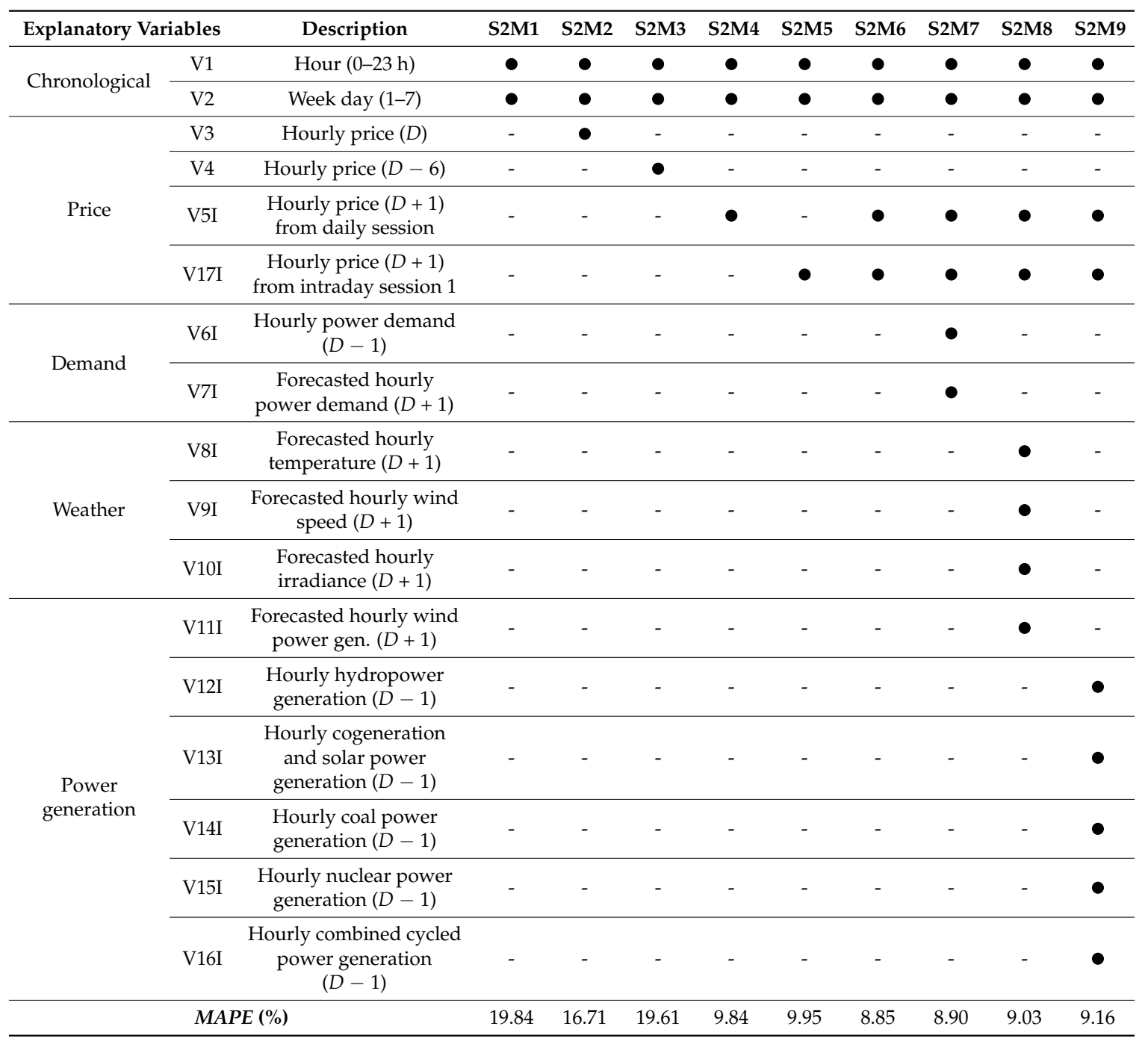

The variable sets related to power demand (V6I and V7I) were tested following a procedure similar to that used for ISMPF models for intraday session 1 ; an error of $8.90 \%$ was obtained with model S2M7. Variables V8I to V11I (forecasted hourly weather variables $D+1$ and forecasted hourly wind power generation $D+1$ ) led to an error of $9.03 \%$ with model S2M8; and variables V12I to V16I (power generations $D-1$ ) obtained an error of $9.16 \%$ with model S2M9. All these variables (V6I, V7I to V11I and V12I to V16I) did not achieve a better performance than the best model S2M6 (with a MAPE of $8.85 \%$ ).

The best forecast error of $8.85 \%$ in model S2M6 for intraday market session 2 was higher than the best forecast error of $7.49 \%$ in model S1M4 for intraday market session 1. However, model S2M6 for intraday market session 2 still presented a significantly better performance than the best model for the daily session (model M18, with an error of $10.69 \%$ as shown in Table 5).

Figure 8 shows an example of the hourly evolution of actual price values and forecast values of model S2M6 for week 7 of year 2013. 


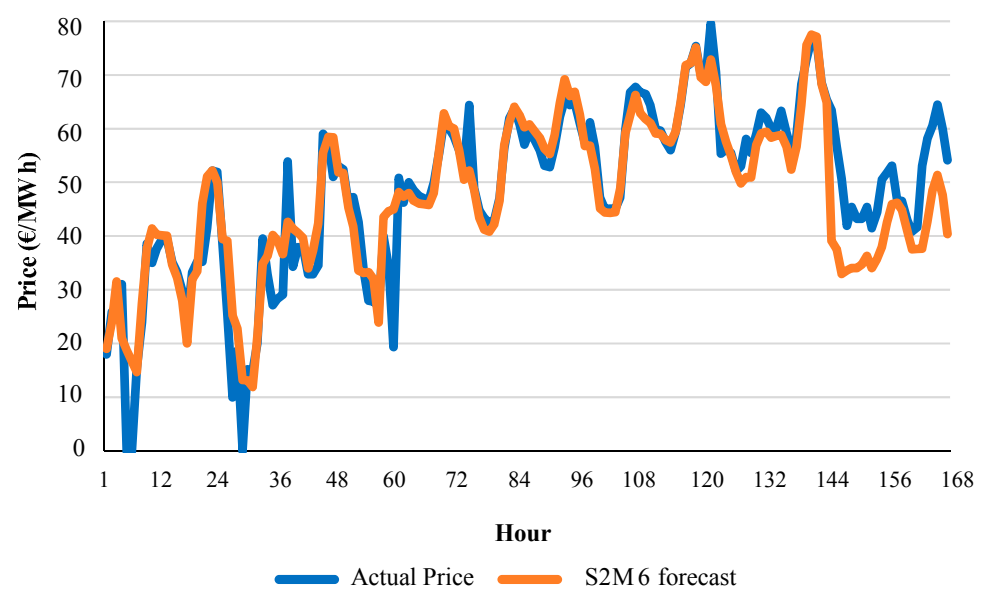

Figure 8. Actual price values and forecast values of model S2M6 of intraday session 2 for week 7 of year 2013.

\subsection{Intraday Market Session 3}

Let us consider that variable V17I (hourly price $D+1$ of intraday session 1 ) and variable V18I (hourly price $D+1$ of intraday session 2) can be available for ISMPF models for intraday market session 3. By applying similar procedures to those used for intraday sessions 1 and 2, the integration of individual price variables (variables V3, V4, V5I, V17I and V18I) of Table 10 within baseline model S3M1 was evaluated. Variables V5I, V17I and V18I led to better MAPEs of models S3M4 to S3M6 (MAPEs between $10.98 \%$ and $9.40 \%$ ) with respect to models S3M2 and S3M3. The best combination of price variables, that is, variables V5I, V17I and V18I, was obtained in model S3M7 for intraday session 3 with a MAPE of $9.30 \%$.

Table 10. ISMPF models for intraday session 3 and their MAPEs.

\begin{tabular}{|c|c|c|c|c|c|c|c|c|c|c|c|c|}
\hline $\begin{array}{r}\text { Explanator } \\
\text { Variables }\end{array}$ & & Description & S3M1 & S3M2 & S3M3 & S3M4 & S3M5 & S3M6 & S3M7 & S3M8 & S3M9 & S3M10 \\
\hline Chronological & $\begin{array}{l}\text { V1 } \\
\text { V2 }\end{array}$ & $\begin{array}{c}\text { Hour }(0-23 \text { h) } \\
\text { Week day }(1-7)\end{array}$ & $\bullet$ & $\bullet$ & $\bullet$ & $\bullet$ & $\bullet$ & $\bullet$ & $\bullet$ & $\bullet$ & $\bullet$ & $\bullet$ \\
\hline \multirow{5}{*}{ Price } & V3 & Hourly price $(D)$ & - & $\bullet$ & - & - & - & - & - & - & - & - \\
\hline & V4 & Hourly price $(D-6)$ & - & - & $\bullet$ & - & - & - & - & - & - & - \\
\hline & V5I & $\begin{array}{l}\text { Hourly price }(D+1) \text { from } \\
\text { daily session }\end{array}$ & - & - & - & $\bullet$ & - & - & $\bullet$ & $\bullet$ & $\bullet$ & $\bullet$ \\
\hline & V17I & $\begin{array}{l}\text { Hourly price }(D+1) \text { from } \\
\text { intraday session } 1\end{array}$ & - & - & - & - & $\bullet$ & - & $\bullet$ & $\bullet$ & $\bullet$ & $\bullet$ \\
\hline & V18I & $\begin{array}{l}\text { Hourly price }(D+1) \text { from } \\
\text { intraday session } 2\end{array}$ & - & - & - & - & - & $\bullet$ & $\bullet$ & $\bullet$ & $\bullet$ & $\bullet$ \\
\hline \multirow{2}{*}{ Demand } & V6I & $\begin{array}{l}\text { Hourly power demand } \\
\qquad(D-1)\end{array}$ & - & - & - & - & - & - & - & $\bullet$ & - & - \\
\hline & V7I & $\begin{array}{c}\text { Forecasted hourly power } \\
\text { demand }(D+1)\end{array}$ & - & - & - & - & - & - & - & $\bullet$ & - & - \\
\hline \multirow{3}{*}{ Weather } & V8I & $\begin{array}{c}\text { Forecasted hourly } \\
\text { temperature }(D+1)\end{array}$ & - & - & - & - & - & - & - & - & $\bullet$ & - \\
\hline & V9I & $\begin{array}{l}\text { Forecasted hourly wind } \\
\text { speed }(D+1)\end{array}$ & - & - & - & - & - & - & - & - & $\bullet$ & - \\
\hline & V10I & $\begin{array}{l}\text { Forecasted hourly } \\
\text { irradiance }(D+1)\end{array}$ & - & - & - & - & - & - & - & - & $\bullet$ & - \\
\hline
\end{tabular}


Table 10. Cont.

\begin{tabular}{|c|c|c|c|c|c|c|c|c|c|c|c|c|}
\hline $\begin{array}{l}\text { Explanatory } \\
\text { Variables }\end{array}$ & & Description & S3M1 & S3M2 & S3M3 & S3M4 & S3M5 & S3M6 & S3M7 & S3M8 & S3M9 & S3M10 \\
\hline \multirow{7}{*}{$\begin{array}{l}\text { Power } \\
\text { generation }\end{array}$} & V11I & $\begin{array}{l}\text { Forecasted hourly wind } \\
\text { power gen. }(D+1)\end{array}$ & - & - & - & - & - & - & - & - & $\bullet$ & - \\
\hline & V12I & $\begin{array}{l}\text { Hourly hydropower } \\
\text { generation }(D-1)\end{array}$ & - & - & - & - & - & - & - & - & - & • \\
\hline & V13I & $\begin{array}{l}\text { Hourly cogeneration and } \\
\text { solar power generation } \\
\qquad(D-1)\end{array}$ & - & - & - & - & - & - & - & - & - & $\bullet$ \\
\hline & V14I & $\begin{array}{l}\text { Hourly coal power } \\
\text { generation }(D-1)\end{array}$ & - & - & - & - & - & - & - & - & - & $\bullet$ \\
\hline & V15I & $\begin{array}{l}\text { Hourly nuclear power } \\
\text { generation }(D-1)\end{array}$ & - & - & - & - & - & - & - & - & - & $\bullet$ \\
\hline & V16I & $\begin{array}{c}\text { Hourly combined cycled } \\
\text { power generation }(D-1)\end{array}$ & - & - & - & - & - & - & - & - & - & $\bullet$ \\
\hline & \multicolumn{2}{|c|}{ MAPE (\%) } & 19.96 & 17.36 & 19.50 & 10.98 & 10.23 & 9.40 & 9.30 & 10.31 & 9.70 & 10.09 \\
\hline
\end{tabular}

The inclusion of variables V6I and V16I with the variables of model S3M7 did not achieve improvements in the error (10.31\% of model S3M8). The integration of variables V8I to V11I in model S3M9 obtained an error of $9.70 \%$; the integration of variables V12I to V16I in model S3M10 led to an error of $10.09 \%$.

Figure 9 shows an example of the hourly evolution of actual price values and forecast values of model S3M7 for week 7 of year 2013.

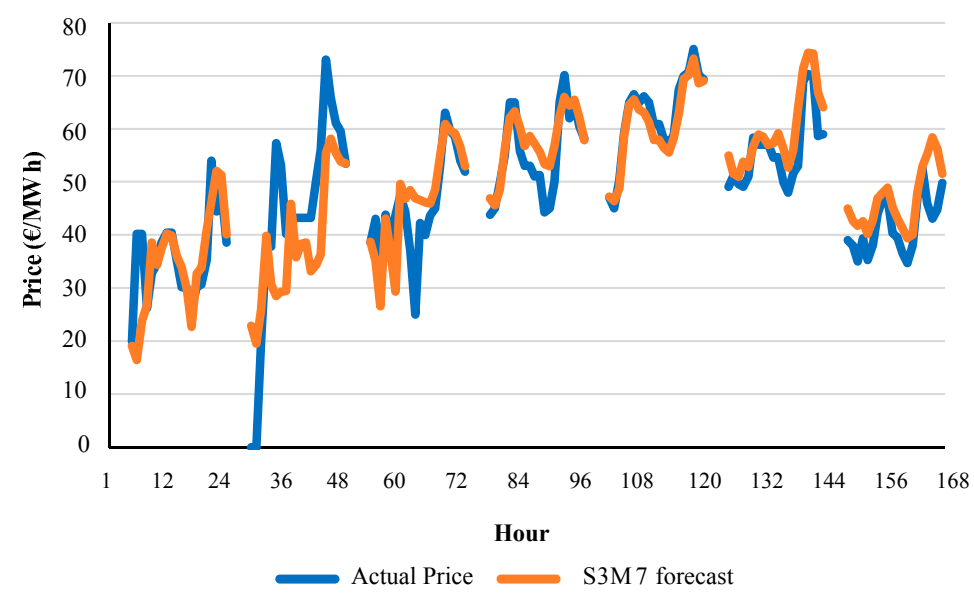

Figure 9. Actual price values and forecast values of model S3M7 of intraday session 3 for week 7 of year 2013.

\subsection{Intraday Market Session 4}

Let us consider that variables V17I, V18I and V19I (hourly prices $D+1$ of intraday sessions 1, 2 and 3) are available for ISMPF models for intraday market session 4 . The analysis of the inclusion of individual variables V5I, V17I, V18I and V19I with chronological variables V1 and V2 of baseline model S5M1 showed that the best model is model S4M8 with a MAPE $9.08 \%$, as shown in Table 11 . This best model follows the pattern of variable combinations of ISMPF models for previous intraday sessions. 
Table 11. ISMPF models for intraday session 4 and their MAPEs.

\begin{tabular}{|c|c|c|c|c|c|c|c|c|c|c|c|c|c|}
\hline Explanatory V & iables & Description & S4M1 & S4M2 & S4M3 & S4M4 & S4M5 & S4M6 & S4M7 & S4M8 & S4M9 & S4M1 & S4M11 \\
\hline \multirow{2}{*}{ Chronological } & V1 & Hour $(0-23 \mathrm{~h})$ & $\bullet$ & $\bullet$ & $\bullet$ & $\bullet$ & $\bullet$ & $\bullet$ & $\bullet$ & $\bullet$ & $\bullet$ & $\bullet$ & $\bullet$ \\
\hline & $\mathrm{V} 2$ & Week day (1-7) & $\bullet$ & $\bullet$ & $\bullet$ & $\bullet$ & $\bullet$ & $\bullet$ & $\bullet$ & $\bullet$ & $\bullet$ & $\bullet$ & $\bullet$ \\
\hline \multirow{6}{*}{ Price } & V3 & Hourly price $(D)$ & - & $\bullet$ & - & - & - & - & - & - & - & - & - \\
\hline & $\mathrm{V} 4$ & Hourly price $(D-6)$ & - & - & $\bullet$ & - & - & - & - & - & - & - & - \\
\hline & V5I & $\begin{array}{l}\text { Hourly price }(D+1) \\
\text { from daily session }\end{array}$ & - & - & - & $\bullet$ & - & - & $\bullet$ & $\bullet$ & $\bullet$ & $\bullet$ & $\bullet$ \\
\hline & V17I & $\begin{array}{l}\text { Hourly price }(D+1) \\
\text { from intraday session } 1\end{array}$ & - & - & - & - & $\bullet$ & & $\bullet$ & $\bullet$ & $\bullet$ & $\bullet$ & $\bullet$ \\
\hline & V18I & $\begin{array}{c}\text { Hourly price }(D+1) \\
\text { from intraday session } 2\end{array}$ & - & - & - & - & - & $\bullet$ & $\bullet$ & $\bullet$ & $\bullet$ & $\bullet$ & - \\
\hline & V19I & $\begin{array}{l}\text { Hourly price }(D+1) \\
\text { from intraday session } 3\end{array}$ & - & - & - & - & - & - & $\bullet$ & • & $\bullet$ & $\bullet$ & $\bullet$ \\
\hline \multirow{2}{*}{ Demand } & V6I & $\begin{array}{l}\text { Hourly power demand } \\
\qquad(D-1)\end{array}$ & - & - & - & - & - & - & - & - & - & - & - \\
\hline & V7I & $\begin{array}{l}\text { Forecasted hourly power } \\
\text { demand }(D+1)\end{array}$ & - & - & - & - & - & - & - & - & - & - & - \\
\hline \multirow{3}{*}{ Weather } & V8I & $\begin{array}{l}\text { Forecasted hourly } \\
\text { temperature }(D+1)\end{array}$ & - & - & - & - & - & - & - & - & - & • & - \\
\hline & V9I & $\begin{array}{l}\text { Forecasted hourly wind } \\
\text { speed }(D+1)\end{array}$ & - & - & - & - & - & - & - & - & - & $\bullet$ & - \\
\hline & V10I & $\begin{array}{l}\text { Forecasted hourly } \\
\text { irradiance }(D+1)\end{array}$ & - & - & - & - & - & - & - & - & - & $\bullet$ & - \\
\hline \multirow{7}{*}{$\begin{array}{l}\text { Power } \\
\text { generation }\end{array}$} & V11I & $\begin{array}{l}\text { Forecasted hourly wind } \\
\text { power generation }(D+1)\end{array}$ & - & - & - & - & - & - & - & - & - & $\bullet$ & - \\
\hline & V12I & $\begin{array}{l}\text { Hourly hydropower } \\
\text { generation }(D-1)\end{array}$ & - & - & - & - & - & - & - & - & - & - & $\bullet$ \\
\hline & V13I & $\begin{array}{l}\text { Hourly cogeneration and } \\
\text { solar power generation } \\
\qquad(D-1)\end{array}$ & - & - & - & - & - & - & - & - & - & - & - \\
\hline & V14I & $\begin{array}{l}\text { Hourly coal power } \\
\text { generation }(D-1)\end{array}$ & - & - & - & - & - & - & - & - & - & - & $\bullet$ \\
\hline & V15I & $\begin{array}{l}\text { Hourly nuclear power } \\
\text { generation }(D-1)\end{array}$ & - & - & - & - & - & - & - & - & - & - & - \\
\hline & V16I & $\begin{array}{l}\text { Hourly combined cycled } \\
\text { power generation } \\
(D-1)\end{array}$ & - & - & - & - & - & - & - & - & - & - & - \\
\hline & \multicolumn{2}{|c|}{ MAPE (\%) } & 19.80 & 16.42 & 19.08 & 11.99 & 10.86 & 10.60 & 10.52 & 9.08 & 9.31 & 9.37 & 9.49 \\
\hline
\end{tabular}

Again, variables V6I and V7I (power demand variables), variables V8I to V11I (forecasted variables) and variables V12I to V16I (power generations) did not improve the MAPE achieved by model S4M8, since they led to errors of 9.31\% (model S4M9), 9.37\% (model S4M10) and 9.49\% (model S4M11).

Figure 10 shows an example of the hourly evolution of actual price values and forecast values of model S4M8 for week 7 of year 2013.

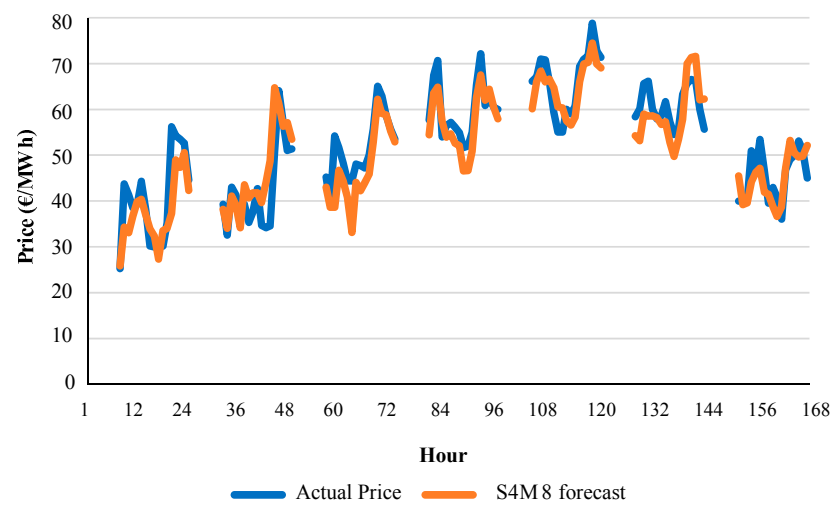

Figure 10. Actual price values and forecast values of model S4M8 of intraday session 4 for week 7 of year 2013. 


\subsection{Intraday Market Session 5}

Let us consider that variables V17I to V20I (hourly prices $D+1$ of intraday sessions 1 to 4 ) are available for ISMPF models for intraday market session 5. ISMPF models for intraday session 5 follow a similar pattern of variable combinations of ISMPF models for previous intraday sessions. The best ISMPF model is S5M9 with a MAPE of $9.52 \%$, as shown in Table 12.

Table 12. ISMPF models for intraday session 5 and their MAPEs.

\begin{tabular}{|c|c|c|c|c|c|c|c|c|c|c|c|c|c|c|}
\hline Explanatory V & riables & Description & S5M1 & S5M2 & S5M3 & S5M4 & S5M5 & S5M6 & S5M7 & S5M8 & S5M9 & S5M10 & S5M11 & S5M12 \\
\hline \multirow{2}{*}{ Chronological } & $\mathrm{V} 1$ & Hour $(0-23 \mathrm{~h})$ & $\bullet$ & $\bullet$ & $\bullet$ & $\bullet$ & $\bullet$ & $\bullet$ & $\bullet$ & $\bullet$ & $\bullet$ & $\bullet$ & $\bullet$ & $\bullet$ \\
\hline & $\mathrm{V} 2$ & Week day (1-7) & $\bullet$ & $\bullet$ & $\bullet$ & $\bullet$ & $\bullet$ & $\bullet$ & $\bullet$ & $\bullet$ & $\bullet$ & $\bullet$ & $\bullet$ & $\bullet$ \\
\hline \multirow{7}{*}{ Price } & V3 & Hourly price $(D)$ & - & $\bullet$ & - & - & - & - & - & - & - & - & - & - \\
\hline & V4 & Hourly price $(D-6)$ & - & - & $\bullet$ & - & - & - & - & - & - & - & - & - \\
\hline & V5I & $\begin{array}{l}\text { Hourly price }(D+1) \text { from } \\
\text { daily session }\end{array}$ & - & - & - & $\bullet$ & - & - & - & - & $\bullet$ & $\bullet$ & $\bullet$ & $\bullet$ \\
\hline & V17I & $\begin{array}{l}\text { Hourly price }(D+1) \text { from } \\
\text { intraday session } 1\end{array}$ & - & - & - & - & $\bullet$ & - & - & - & $\bullet$ & $\bullet$ & $\bullet$ & $\bullet$ \\
\hline & V18I & $\begin{array}{l}\text { Hourly price }(D+1) \text { from } \\
\text { intraday session } 2\end{array}$ & - & - & - & - & - & $\bullet$ & - & - & $\bullet$ & $\bullet$ & $\bullet$ & $\bullet$ \\
\hline & V19I & $\begin{array}{l}\text { Hourly price }(D+1) \text { from } \\
\quad \text { intraday session } 3\end{array}$ & - & - & - & - & - & - & $\bullet$ & - & $\bullet$ & $\bullet$ & $\bullet$ & $\bullet$ \\
\hline & V20I & $\begin{array}{l}\text { Hourly price }(D+1) \text { from } \\
\text { intraday session } 4\end{array}$ & - & - & - & - & - & - & - & $\bullet$ & $\bullet$ & $\bullet$ & $\bullet$ & $\bullet$ \\
\hline \multirow{2}{*}{ Demand } & V6I & $\begin{array}{l}\text { Hourly power demand } \\
\qquad(D-1)\end{array}$ & - & - & - & - & - & - & - & - & - & $\bullet$ & - & - \\
\hline & V7I & $\begin{array}{l}\text { Forecasted hourly power } \\
\text { demand }(D+1)\end{array}$ & - & - & - & - & - & - & - & - & - & $\bullet$ & - & - \\
\hline \multirow{3}{*}{ Weather } & V8I & $\begin{array}{l}\text { Forecasted hourly } \\
\text { temperature }(D+1)\end{array}$ & - & - & - & - & - & - & - & - & - & - & $\bullet$ & - \\
\hline & V9I & $\begin{array}{l}\text { Forecasted hourly wind } \\
\text { speed }(D+1)\end{array}$ & - & - & - & - & - & - & - & - & - & - & $\bullet$ & - \\
\hline & V10I & $\begin{array}{l}\text { Forecasted hourly } \\
\text { irradiance }(D+1)\end{array}$ & - & - & - & - & - & - & - & - & - & - & $\bullet$ & - \\
\hline \multirow{6}{*}{$\begin{array}{l}\text { Power } \\
\text { generation }\end{array}$} & V11I & $\begin{array}{l}\text { Forecasted hourly wind } \\
\text { power generation }(D+1)\end{array}$ & - & - & - & - & - & - & - & - & - & - & $\bullet$ & - \\
\hline & V12I & $\begin{array}{l}\text { Hourly hydropower } \\
\text { generation }(D-1)\end{array}$ & - & - & - & - & - & - & - & - & - & - & - & $\bullet$ \\
\hline & V13I & $\begin{array}{l}\text { Hourly cogeneration and } \\
\text { solar power generation } \\
\qquad(D-1)\end{array}$ & - & - & - & - & - & - & - & - & - & - & - & $\bullet$ \\
\hline & V14I & $\begin{array}{l}\text { Hourly coal power } \\
\text { generation }(D-1)\end{array}$ & - & - & - & - & - & - & - & - & - & - & - & $\bullet$ \\
\hline & V15I & $\begin{array}{l}\text { Hourly nuclear power } \\
\text { generation }(D-1)\end{array}$ & - & - & - & - & - & - & - & - & - & - & - & $\bullet$ \\
\hline & V16I & $\begin{array}{l}\text { Hourly combined cycled } \\
\text { power generation }(D-1)\end{array}$ & - & - & - & - & - & - & - & - & - & - & - & $\bullet$ \\
\hline \multicolumn{3}{|c|}{ MAPE (\%) } & 19.62 & 16.16 & 19.37 & 12.17 & 11.47 & 11.07 & 10.40 & 10.18 & 9.52 & 9.53 & 9.69 & 10.16 \\
\hline
\end{tabular}

A MAPE of $12.17 \%$ was obtained with model S5M4 by using information from the daily session (variable V5I) in Table 12; an error of $11.47 \%$ with model S5M5 when using information from intraday session 1 (variable V17I); 11.07\% with model S5M6 by using information from intraday session 2 (variable V18I); 10.40\% with model S5M7 by using information from intraday session 3 (variable V19I); and an error of $10.18 \%$ was obtained with model S5M8 when using information from intraday session 4 (variable V20I). Therefore, the evolution of the MAPE from model S5M4 to model S5M8 in Table 12 indicates a progressive reduction in the forecasting error with the use of more updated information (hourly price $D+1$ of the previous intraday sessions).

The integration of variables V6I and V7I in model S5M10 resulted in a MAPE of 9.53\%. The consideration of variables V8I to V11I in model S5M11 led to an error of 9.69\%. The inclusion of variables V12I to V16I in model S5M12 achieved an error of 10.16\%. All these error values obtained by including additional variables V6I, V7I, V8I to V11I, and V12I to V16I to model S5M9 were higher than the error (9.52\%) of the best ISMPF model (model S5M9) for intraday session 5. 
Figure 11 shows an example of the hourly evolution of actual price values and forecast values of model S5M9 for week 7 of year 2013.

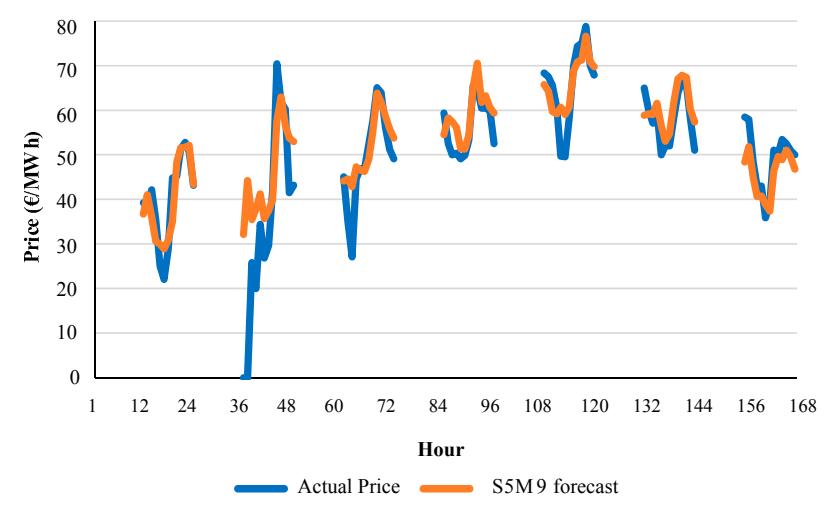

Figure 11. Actual price values and forecast values of model S5M9 of intraday session 5 for week 7 of year 2013.

\subsection{Intraday Market Session 6}

Let consider that variables V17I to V21I (hourly prices $D+1$ of intraday sessions 1 to 5 ) are available for ISMPF models for intraday market session 6. ISMPF models for intraday session 6 follow a different pattern of variable combinations from that of ISMPF models for previous intraday sessions. As shown in Table 13, there are eight possible price variables: price $D$ (variable V3); price $D-6$ (variable V4); price $D+1$ of daily session (variable V5I); and prices $D+1$ of previous intraday sessions 1 to 5 (variables V17I to V21I). Variables V3 and V4 in models S6M2 and S6M3 improved the MAPE with respect to that of model S6M1. The evolution of the MAPE from model S6M4 to model S6M9 in Table 13, with a reduction from $15.35 \%$ of model S6M4 to $12.73 \%$ of model S6M9, indicates a progressive decrease in the $M A P E$ due to the inclusion of more updated information.

Table 13. ISMPF models for intraday session 6 and their MAPEs.

\begin{tabular}{|c|c|c|c|c|c|c|c|c|c|c|c|c|c|c|c|c|c|c|}
\hline $\begin{array}{c}\text { Explanatory } \\
\text { Variables }\end{array}$ & & S6M1 & S6M2 & S6M3 & S6M4 & S6M5 & S6M6 & $56 \mathrm{M} 7$ & S6M8 & S6M9 & S6M10 & S6M11 & S6M12 & S6M13 & S6M14 & S6M1 & S6M16 & S6M17 \\
\hline \multirow{2}{*}{ Chronological } & V1 & $\bullet$ & $\bullet$ & $\bullet$ & $\bullet$ & $\bullet$ & $\bullet$ & $\bullet$ & $\bullet$ & $\bullet$ & $\bullet$ & $\bullet$ & $\bullet$ & $\bullet$ & $\bullet$ & $\bullet$ & $\bullet$ & $\bullet$ \\
\hline & V2 & $\bullet$ & $\bullet$ & $\bullet$ & $\bullet$ & $\bullet$ & $\bullet$ & $\bullet$ & $\bullet$ & $\bullet$ & $\bullet$ & $\bullet$ & $\bullet$ & $\bullet$ & $\bullet$ & $\bullet$ & $\bullet$ & $\bullet$ \\
\hline \multirow{8}{*}{ Price } & V3 & - & $\bullet$ & - & - & - & - & - & - & - & - & - & - & - & - & - & - & - \\
\hline & V4 & - & - & $\bullet$ & - & - & - & - & - & - & - & - & - & - & - & - & - & - \\
\hline & V5I & - & - & - & $\bullet$ & - & - & - & - & - & - & - & - & - & $\bullet$ & - & - & - \\
\hline & V17I & - & - & - & - & $\bullet$ & - & - & - & - & - & - & - & $\bullet$ & $\bullet$ & - & - & - \\
\hline & V18I & - & - & - & - & - & $\bullet$ & - & - & - & - & & $\bullet$ & $\bullet$ & $\bullet$ & - & - & - \\
\hline & V19I & - & - & - & - & - & - & $\bullet$ & - & - & - & $\bullet$ & $\bullet$ & $\bullet$ & $\bullet$ & $\bullet$ & $\bullet$ & $\bullet$ \\
\hline & V20I & - & - & - & - & - & - & - & $\bullet$ & - & - & $\bullet$ & $\bullet$ & $\bullet$ & $\bullet$ & $\bullet$ & $\bullet$ & $\bullet$ \\
\hline & V21I & - & - & - & - & - & - & - & - & $\bullet$ & $\bullet$ & $\bullet$ & $\bullet$ & $\bullet$ & $\bullet$ & $\bullet$ & $\bullet$ & $\bullet$ \\
\hline \multirow{2}{*}{ Demand } & V6I & - & - & - & - & - & - & - & - & - & - & - & - & - & - & $\bullet$ & - & - \\
\hline & V7I & - & - & - & - & - & - & - & - & - & - & - & - & - & - & $\bullet$ & - & - \\
\hline \multirow{3}{*}{ Weather } & V8I & - & - & - & - & - & - & - & - & - & - & - & - & - & - & - & $\bullet$ & - \\
\hline & V9I & - & - & - & - & - & - & - & - & - & - & - & - & - & - & - & $\bullet$ & - \\
\hline & V10I & - & - & - & - & - & - & - & - & - & - & - & - & - & - & - & $\bullet$ & - \\
\hline \multirow{6}{*}{$\begin{array}{l}\text { Power } \\
\text { generation }\end{array}$} & V11I & - & - & - & - & - & - & - & - & - & - & - & - & - & - & - & $\bullet$ & - \\
\hline & V12I & - & - & - & - & - & - & - & - & - & - & - & - & - & - & - & - & $\bullet$ \\
\hline & V13I & - & - & - & - & - & - & - & - & - & - & - & - & - & - & - & - & $\bullet$ \\
\hline & V14I & - & - & - & - & - & - & - & - & - & - & - & - & - & - & - & - & $\bullet$ \\
\hline & V15I & - & - & - & - & - & - & - & - & - & - & - & - & - & - & - & - & $\bullet$ \\
\hline & V16I & - & - & - & - & - & - & - & - & - & - & - & - & - & - & - & - & $\bullet$ \\
\hline MAPE (\%) & & 21.41 & 18.11 & 20.88 & 15.35 & 14.69 & 14.30 & 13.41 & 13.10 & 12.73 & 12.69 & 12.48 & 12.70 & 12.90 & 12.93 & 12.78 & 13.00 & 13.99 \\
\hline
\end{tabular}


On the contrary to previous intraday sessions, the best ISMPF model for intraday session 6 does not use the combination of all the price $D+1$ variables of previous intraday sessions and the price $D+1$ of the daily session. The best MAPE of $12.48 \%$ was achieved with model S6M11 by including variables V19I to V21I corresponding to the previous three intraday sessions (intraday sessions 3, 4 and 5).

A suitable analysis, similar to that carried out for the other intraday sessions, allowed to determine that model S6M15 (including variables V6I and V7I) led to a higher MAPE (12.78\%) than error $12.48 \%$ of the best model S6M11; model S6M16 (adding variables V8I to V11I) obtained an error of 13\%; and model S6M17 (including variables V12I to V16I) resulted in an error of $13.99 \%$.

Figure 12 shows an example of the hourly evolution of actual price values and forecast values of model S6M11 for week 7 of year 2013.

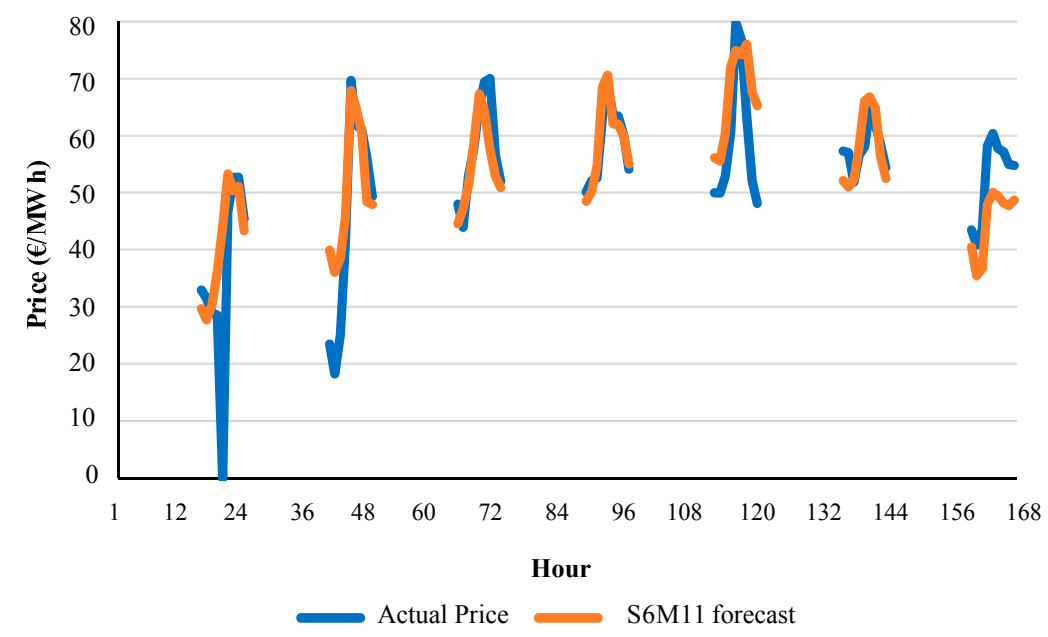

Figure 12. Actual price values and forecast values of model S6M11 of intraday session 6 for week 7 of year 2013.

\subsection{Comparison of the Best ISMPF Models with the Best DSMPF Model}

Table 14 shows the best ISMPF models and the best DSMPF model, including the corresponding main characteristics and the MAPEs. The error increased from the best model S1M4 of intraday session 1 (error of $7.49 \%$ ) to the best model S6M11 for intraday session 6 (error of 12.48\%). Error $10.69 \%$ of model M18 (the best DSMPF model) was higher than most of the errors of the best ISMPF models for intraday sessions (intraday sessions 1 to 5), although the main characteristics of the best ISMPF models for intraday sessions were different from those of the best DSMPF model for the daily session.

Table 14. The best ISMPF models and the best DSMPF model.

\begin{tabular}{cccc}
\hline Forecasting Session for MIBEL & Forecasting Period & Best Forecasting Model & MAPE (\%) \\
\hline Daily session & $0 \mathrm{~h}(D+1)$ to $23 \mathrm{~h}(D+1)$ & $\mathrm{M} 18$ & 10.69 \\
Intraday session 1 & $21 \mathrm{~h}(D)$ to $23 \mathrm{~h}(D+1)$ & S1M4 & 7.49 \\
Intraday session 2 & $0 \mathrm{~h}(D+1)$ to $23 \mathrm{~h}(D+1)$ & S2M6 & 8.85 \\
Intraday session 3 & $4 \mathrm{~h}(D+1)$ to $23 \mathrm{~h}(D+1)$ & S3M7 & 9.30 \\
Intraday session 4 & $7 \mathrm{~h}(D+1)$ to $23 \mathrm{~h}(D+1)$ & S4M8 & 9.08 \\
Intraday session 5 & $11 \mathrm{~h}(D+1)$ to $23 \mathrm{~h}(D+1)$ & S5M9 & 9.52 \\
Intraday session 6 & $15 \mathrm{~h}(D+1)$ to $23 \mathrm{~h}(D+1)$ & S6M11 & 12.48 \\
\hline
\end{tabular}

\section{Conclusions}

This paper presents novel ISMPF models for hourly price forecasting of the six intraday sessions of the MIBEL as well as a systematic analysis of the MAPEs corresponding to suitable combinations of their input variables in order to determine the best ISMPF model for each of the sessions, that is, the best combination of input variables for ISMPF models in each intraday session. 
The methodology of the analysis is initially applied to DSMPF for the day-ahead hourly price forecasting, in the daily session of the MIBEL, and also applied to RMPE models for the estimation of the hourly prices.

DSMPF models use as input variables (price explanatory variables) recorded time series of hourly prices in previous days, regional-aggregated hourly power demands and hourly power generations of most of the types of electricity production in the previous day, forecasts of demand, wind power generation and weather (hourly wind speed, temperature and irradiation) for the day-ahead in the region, and chronological variables.

The main difference between the RMPE models and DSMPF models is that RMPE models use actual power generation values and actual power demand values of the day-ahead instead of the values of these variables on the previous day. Thus, RMPE models are not models for price forecast, but for price estimation.

Both DSMPF and RMPE models were satisfactorily applied to the real-life case study of the MIBEL that covers the mainland of Portugal and Spain. Descriptive statistics of price data have been provided. The MAPE of the best RMPE model was $9.9 \%$; it represents the lowest limit of the MAPE of any RMPE model for price estimation or any DSMPF model for price forecast, using the same kind of input variables of RMPE models.

The MAPE of the best DSMPF model (model M18) was $10.7 \%$, very close to the "minimum error" (9.9\%) obtained by the best RMPE model, showing a very satisfactory performance of the best DSMPF model.

The ISMPF models consider the input variables included in DSMPF models as well as the hourly prices of the daily session and hourly prices of previous intraday sessions of the MIBEL. The methodology of the analysis used for DSMPF models is also applied to ISMPF models to find the combination of input variables that achieves the best MAPE for each intraday session of the MIBEL in order to determine the best ISMPF model.

The MAPE varied from $7.49 \%$ of the best ISMPF model (model S1M4) for the intraday session 1 to $9.52 \%$ of the best ISMPF model (model S5M9) for the intraday session 5; it raised to $12.48 \%$ of the best ISMPF model (model S6M11) for the intraday session 6. Thus, the MAPE of the best ISMPF models for intraday sessions 1 to 5 were clearly better than the error of $10.7 \%$ of the best DSMPF model.

The best ISMPF models for intraday sessions 1 to 5 use only the hourly prices of the daily session and hourly prices of previous intraday sessions, as well as chronological variables, and they are therefore significantly simpler than the best DSMPF model. On the other hand, the best ISMPF model of intraday session 6 exclusively utilizes the hourly prices of previous intraday sessions 3, 4 and 5, and the chronological variables, and it is also considerably simpler than the best DSMPF model.

The best Intraday Session Model for Price Forecasts of this paper, their performance in the MIBEL mainly in terms of $M A P E$, and the determination of their best input variables can be useful for agents of the electricity intraday market and the electric energy industry.

Acknowledgments: The authors would like to thank the "Ministerio de Economia y Competitividad" of the Spanish Government for supporting this research under the Project ENE2013-48517-C2-2-R, the Project ENE2013-48517-C2-1-R and the ERDF funds of the European Union; and to thank the company Smartwatt (swi.smartwatt.net) for providing data and practical experience associated with the models of this paper.

Author Contributions: All the authors contributed equally to this work.

Conflicts of Interest: The authors declare no conflict of interest.

\section{References}

1. Bello, A.; Reneses, J.; Muñoz, A. Medium-term probabilistic forecasting of extremely low prices in electricity markets: Application to the Spanish case. Energies 2016, 9, 193. [CrossRef]

2. The Iberian Energy Derivatives Exchange, OMIP. Available online: http://www.omip.pt (accessed on 25 May 2016). 
3. Market Operator of the Iberian Electricity Market, OMEI. Available online: http://www.omie.es (accessed on 25 May 2016).

4. Hellmers, A.; Zugno, M.; Skajaa, A.; Morales, J.M. Operational strategies for a portfolio of wind farms and CHP plants in a two-price balancing market. IEEE Trans. Power Syst. 2016, 31, 2182-2191. [CrossRef]

5. Moreno, M.A.; Bueno, M.; Usaola, J. Evaluating risk-constrained bidding strategies in adjustment spot markets for wind power producers. Int. J. Electr. Power Energy Syst. 2012, 43, 703-711. [CrossRef]

6. Morales, J.M.; Conejo, A.J.; Pérez-Ruiz, J. Short-term trading for a wind power producer. IEEE Trans. Power Syst. 2010, 25, 554-564. [CrossRef]

7. Zugno, M.; Morales, J.M.; Pinson, P.; Madsen, H. Pool strategy of a price-maker wind power producer. IEEE Trans. Power Syst. 2013, 28, 3440-3450. [CrossRef]

8. Shafie-Khah, M.; Heydarian-Forushani, E.; Golshan, M.E.H.; Moghaddam, M.P.; Sheikh-El-Eslami, M.K.; Catalão, J.P.S. Strategic offering for a price-maker wind power producer in oligopoly markets considering demand response exchange. IEEE Trans. Ind. Inform. 2015, 11, 1542-1553. [CrossRef]

9. Ding, H.; Hu, Z.; Song, Y.; Pinson, P. Improving offering strategies for wind farms enhanced with storage capability. In Proceedings of the 2015 IEEE Eindhoven PowerTech, Eindhoven, The Netherlands, 29 June-2 July 2015.

10. Ferruzzi, G.; Cervone, G.; Delle Monache, L.; Graditi, G.; Jacobone, F. Optimal bidding in a Day-Ahead energy market for Micro Grid under uncertainty in renewable energy production. Energy 2016, 106, 194-202. [CrossRef]

11. Conejo, A.J.; Carrión, M.; Morales, J.M. Decision Making under Uncertainty in Electricity Markets; Springer: New York, NY, USA, 2010.

12. Chan, S.C.; Tsui, K.M.; Wu, H.C.; Hou, Y.; Wu, Y.-C.; Wu, F.F. Load/price forecasting and managing demand response for smart grids: Methodologies and challenges. IEEE Signal Process. Mag. 2012, 29, 68-85. [CrossRef]

13. Ghasemi, A.; Shayeghi, H.; Moradzadeh, M.; Nooshyar, M. A novel hybrid algorithm for electricity price and load forecasting in smart grids with demand-side management. Appl. Energy 2016, 177, 40-59. [CrossRef]

14. Chen, Z.; Wu, L.; Fu, Y. Real-time price-based demand response management for residential appliances via stochastic optimization and robust optimization. IEEE Trans. Smart Grid 2012, 3, 1822-1831. [CrossRef]

15. Research Network for Distributed Energy Resources and for Distributed Demand Resources in the Horizon of Year 2050 (Project ENE2015-70032-REDT). Available online: http:/ /www.redyd2050-der.eu (accessed on 25 May 2016).

16. European Technology Platform on Smartgirds. Consolidated View of the ETP SG on Research, Development \& Demonstration Needs in the Horizon 2020 Work Programme 2016-2017. Available online: http:/ /www. smartgrids.eu/ETP\%20Smartgrids\%20View\%20on\%20H2020\%20WP16-17.pdf (accessed on 25 May 2016).

17. Smart Energy Demand Coalition, Mapping Demand Response in Europe Today 2015. Available online: http:/ / www.smartenergydemand.eu (accessed on 25 May 2016).

18. Contreras, J.; Espínola, R.; Nogales, F.J.; Conejo, A.J. ARIMA models to predict next-day electricity prices. IEEE Trans. Power Syst. 2003, 18, 1014-1020. [CrossRef]

19. Cruz, A.; Muñoz, A.; Zamora, J.L.; Espinola, R. The effect of wind generation and weekday on Spanish electricity spot price forecasting. Electr. Power Syst. Res. 2011, 81, 1924-1935. [CrossRef]

20. Dong, Y.; Wang, J.; Jiang, H.; Wu, J. Short-term electricity price forecast based on the improved hybrid model. Energy Convers. Manag. 2011, 52, 2987-2995. [CrossRef]

21. Tan, Z.; Zhang, J.; Wang, J.; Xu, J. Day-ahead electricity price forecasting using wavelet transform combined with ARIMA and GARCH models. Appl. Energy 2010, 87, 3606-3610. [CrossRef]

22. Shrivastava, N.A.; Khosravi, A.; Panigrahi, B.K. Prediction interval estimation of electricity prices using PSO-tuned support vector machines. IEEE Trans. Ind. Inform. 2015, 11, 322-331. [CrossRef]

23. Catalão, J.P.S.; Mariano, S.J.P.S.; Mendes, V.M.F.; Ferreira, L.A.F.M. Short-term electricity prices forecasting in a competitive market: A neural network approach. Electr. Power Syst. Res. 2007, 77, 1297-1304. [CrossRef]

24. Singhal, D.; Swarup, K.S. Electricity price forecasting using artificial neural networks. Int. J. Electr. Power Energy Syst. 2011, 33, 550-555. [CrossRef]

25. Panapakidis, I.P.; Dagoumas, A.S. Day-ahead electricity price forecasting via the application of artificial neural network based models. Appl. Energy 2016, 172, 132-151. [CrossRef]

26. Arciniegas, A.I.; Arciniegas Rueda, I.E. Forecasting short-term power prices in the Ontario Electricity Market (OEM) with a fuzzy logic based inference system. Util. Policy 2008, 16, 39-48. [CrossRef] 
27. Motamedi, A.; Zareipour, H.; Rosehart, W.D. Electricity price and demand forecasting in smart grids. IEEE Trans. Smart Grid 2012, 3, 664-674. [CrossRef]

28. Pousinho, H.M.I.; Mendes, V.M.F.; Catalão, J.P.S. Short-term electricity prices forecasting in a competitive market by a hybrid PSO-ANFIS approach. Int. J. Electr. Power Energy Syst. 2012, 39, 29-35. [CrossRef]

29. Sharma, V.; Srinivasan, D. A hybrid intelligent model based on recurrent neural networks and excitable dynamics for price prediction in deregulated electricity market. Eng. Appl. Artif. Intell. 2013, 26, 1562-1574. [CrossRef]

30. Mandal, P.; Haque, A.U.; Meng, J.; Srivastava, A.K.; Martinez, R. A novel hybrid approach using wavelet, firefly algorithm, and fuzzy ARTMAP for day-ahead electricity price forecasting. IEEE Trans. Power Syst. 2013, 28, 1041-1051. [CrossRef]

31. Osório, G.J.; Matias, J.C.O.; Catalão, J.P.S. Electricity prices forecasting by a hybrid evolutionary-adaptive methodology. Energy Convers. Manag. 2014, 80, 363-373. [CrossRef]

32. Jin, C.H.; Pok, G.; Lee, Y.; Park, H.-W.; Kim, K.D.; Yun, U.; Ryu, K.H. A SOM clustering pattern sequence-based next symbol prediction method for day-ahead direct electricity load and price forecasting. Energy Convers. Manag. 2015, 90, 84-92. [CrossRef]

33. Monteiro, C.; Fernandez-Jimenez, L.A.; Ramirez-Rosado, I.J. Explanatory information analysis for day-ahead price forecasting in the Iberian electricity market. Energies 2015, 8, 10464-10486. [CrossRef]

34. Weron, R. Electricity price forecasting: A review of the state-of-the-art with a look into the future. Int. J. Forecast. 2014, 30, 1030-1081. [CrossRef]

35. Bueno, M.; Moreno, M.A.; Usaola, J.; Nogales, F.J. Strategic Wind Energy Bidding in Adjustment Markets. In Proceedings of the 45th International Universities Power Engineering Conference (UPEC), Cardiff, UK, 31 August-3 September 2010.

36. Chaves-Avila, J.P.; Hakvoort, R.A.; Ramos, A. Short-term strategies for Dutch wind power producers to reduce imbalance costs. Energy Policy 2013, 52, 573-582. [CrossRef]

37. Aïd, R.; Grue, P.; Pham, H. An optimal trading problem in intraday electricity markets. Math. Financ. Econ. 2016, 10, 49-85. [CrossRef]

38. Skajaa, A.; Edlund, K.; Morales, J.M. Intraday trading of wind energy. IEEE Trans. Power Syst. 2015, 30, 3181-3189. [CrossRef]

39. Weron, R. Modeling and Forecasting Electricity Loads and Prices: A Statistical Approach; John Wiley \& Sons Ltd.: Oxford, UK, 2006.

40. Furió, D. A survey on the Spanish Electricity Intraday Market. Estud. Econ. Apl. 2011, 29, 1-20.

41. Ciarreta, A.; Zarraga, A. Volatility Transmissions in the Spanish Intra-Day Electricity Market. In Proceedings of the 12th International Conference on the European Energy Market (EEM), Lisbon, Portugal, 19-22 May 2015.

42. Redes Energéticas Nacionais (REN). Portuguese Transmission System Operator. Available online: http:/ / www.centrodeinformacao.ren.pt (accessed on 25 May 2016).

43. Red Eléctrica de España (REE). Spanish Transmission System Operator. Available online: http://www.ree. es/es/actividades/demanda-y-produccion-en-tiempo-real (accessed on 25 May 2016).

44. Janjic, Z.; Black, T.; Pyle, M.; Ferrier, B.; Chuang, H.Y.; Jovic, D.; Mckee, N.; Rozumalski, R.; Michalakes, J.; Gill, D.; et al. NMM Version 3 Modeling System User's Guide. Available online: http://www.dtcenter.org/ wrf-nmm/users/docs/user_guide/V3/users_guide_nmm_chap1-7.pdf (accessed on 25 May 2016).

45. Global Forecast System (GFS). Environmental Modeling Center, National Weather Service. Available online: http:/ / www.emc.ncep.noaa.gov/index.php?branch=GFS (accessed on 25 May 2016).

46. Almeida, L.B. Multilayer Perceptrons. In Handbook of Neural Computation; Fiesler, E., Beale, R., Eds.; Oxford University Press: Oxford, UK, 1997.

47. Hashem, S. Optimal linear combinations of neural networks. Neural Netw. 1997, 10, 599-614. [CrossRef]

(C) 2016 by the authors; licensee MDPI, Basel, Switzerland. This article is an open access article distributed under the terms and conditions of the Creative Commons Attribution (CC-BY) license (http://creativecommons.org/licenses/by/4.0/). 